



\title{
Guía Estadounidense para el Cumplimiento de Requerimientos para Textiles de Línea Hogar y de Vestuario
}

\author{
Lisa M. Benson \\ Karen Reczek
}

Esta publicación se encuentra disponible de forma gratuita en:

https://doi.org/10.6028/NIST.IR.8115es 

NISTIR 8115

\section{Guía Estadounidense para el Cumplimiento de Requerimientos para Textiles de Línea Hogar y de Vestuario}

Lisa M. Benson*

Karen Reczek

Coordinación de Normas

* Dakota Consulting

Esta publicación se encuentra disponible de forma gratuita en:

https://doi.org/10.6028/NIST.IR.8115es

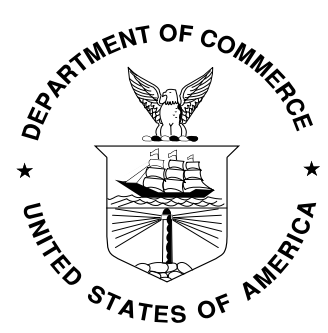

Departamento de Comercio de los Estados Unidos

Wilbur L. Ross, Jr., Secretaria de Comercio

Instituto Nacional de Normas y Tecnología 


\section{Agradecimientos}

La autora principal del presente documento es Lisa M. Benson, Dakota Consulting, bajo contrato para la Coordinación de Normas del Instituto Nacional de Normas y Tecnología NIST. La orientación adicional, investigación inicial y revisión del documento la prestó el personal de la Coordinación de Normas del NIST, incluyendo a Mary Donaldson y a Karen Reczek. También se recibió colaboración invaluable de expertos de la Comisión de Seguridad de Productos del Consumidor y de la Comisión Federal de Comercio que contribuyeron con este documento y llevaron a cabo una revisión exhaustiva. Los revisores por parte de la Comisión de Seguridad de Productos del Consumidor fueron Patty Edwards y Arlene Flecha Castro. Los revisores por parte de la Comisión Federal de Comercio fueron Steve Ecklund y Robert Frisby.

\section{Disclaimer}

This document was translated courtesy of the National Institute of Standards and Technology (NIST). The translation of this document was made by Ingesonic Ltd. with support from the ANSI Standards Alliance program.

This translation is not an official US Government or NIST translation. The US Government does not make any representations as to the accuracy of the translation.

The official English language version of this publication is available free of charge from the National Institute of Standards and Technology (NIST): https://doi.org/10.6028/NIST.IR.8115

\section{Renuncia}

Este documento fue traducido por cortesía del Instituto Nacional de Normas y Tecnología (NIST). La traducción de este documento fue realizada por Ingesonic Ltd. con el apoyo del programa ANSI Standards Alliance.

Esta traducción no es una traducción oficial del Gobierno de los Estados Unidos ni del NIST. El Gobierno de los Estados Unidos no hace ninguna declaración sobre la exactitud de la traducción.

La versión oficial en inglés de esta publicación está disponible gratuitamente en el Instituto Nacional de Estándares y Tecnología (NIST): https://doi.org/10.6028/NIST.IR.8115 


\section{Contenido}

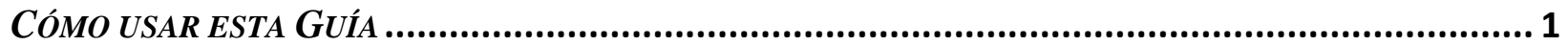

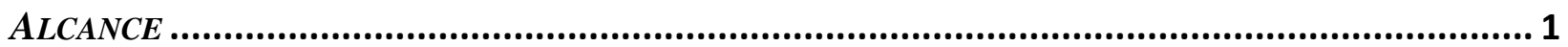

GENERALIDADES DEL MARCO REGLAMENTARIO FEDERAL DE LOS ESTADOS UNIDOS.................. 1

AUTORIDADES REGULADORAS FEDERALES Y REGLAMENTOS TÉCNICOS (OBLIGATORIOS) ........... 2

Comisión de Seguridad de Productos del Consumidor (CPSC) .............................................. 2

Ley de Seguridad de Productos de Consumo (CPSA) ..................................................................... 2

Ley de Mejoramiento de la Seguridad de Productos de Consumo de 2008 (CPSIA) .................. 2

Únicamente Prendas para Niños y Prendas de Dormir ................................................................... 3

Certificados y Pruebas Obligatorias de Terceros …......................................................................... 3

Etiquetas de Rastreo en Prendas para Niños ................................................................................... 4

Sillas Suaves para Bebés y Niños Pequeños ………...................................................................... 4

Cordones en Prendas Infantiles para la Parte Superior del Cuerpo................................................. 5

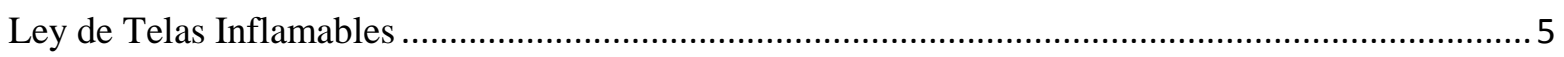

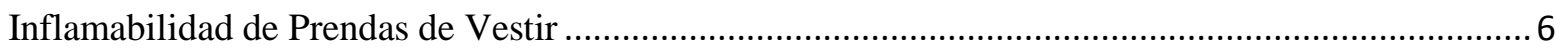

Inflamabilidad de Película de Vinilo .................................................................................. 6

Inflamabilidad de las Prendas de Dormir para Niños ................................................................ 6

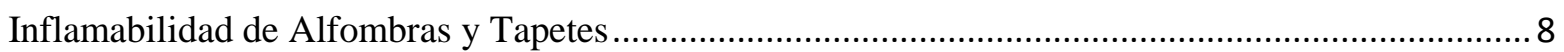

Inflamabilidad de Juegos para Colchón, Colchones, y Protectores para Colchón ................................ 8

Ley Federal de Sustancias Peligrosas (FHSA) ............................................................................... 10

Puntas y Bordes Filosos en Productos para Niños ........................................................................ 11

Prohibición en Cojines para Bebés ............................................................................................... 11

Norma Sobre Cubiertas de Ventanas y Cuerdas ........................................................................... 11

Reglamentos Pendientes de Notificación .................................................................................... 12

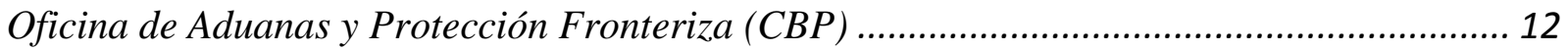

País de origen: Marcado de Artículos Importados y Contenedores ................................................... 12

Agencia de Protección Ambiental (EPA) ............................................................................ 13

Prendas Antimicrobianas y Textiles para el Hogar: Ley Federal para Insecticidas, Fungicidas y Venenos para Roedores (FIFRA) .............................................................................................. 13

Ley de Control de Sustancias Tóxicas (TSCA) ........................................................................... 13

Comisión Federal de Comercio (FTC) ........................................................................ 14

Ley de la Comisión Federal de Comercio (FTC) ............................................................................ 14

Ley de Identificación de Productos de Fibra Textil ....................................................................... 14 
Relleno Usado o de Segunda Mano ........................................................................................ 16

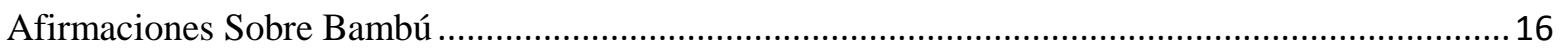

Ley de 1939 sobre el Etiquetado de Productos de Lana .................................................................17

Ley sobre el Etiquetado de Productos de Piel (FPLA) ....................................................................... 18

Ley de 2010 sobre Información Real en el Etiquetado de Pieles ..................................................... 18

Productos de Piel de Perro y Gato ............................................................................................. 19

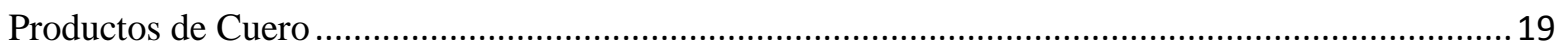

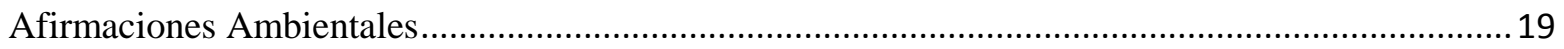

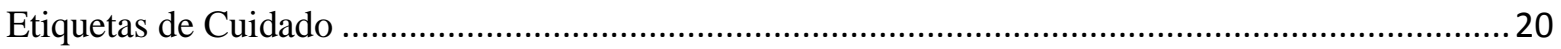

Reglamentos Pendientes de Notificación.................................................................................... 20

Departamento de Agricultura de los Estados Unidos (USDA)........................................ 21

Fibras Ecológicas: Ley de 1990 sobre la Producción de Alimentos Ecológicos (OFPA) ..................21

GENERALIDADES DE LOS MARCOS REGLAMENTARIOS DEL ESTADO ESTADOUNIDENSE .............. 21 AUTORIDADES REGULADORAS ESTATALES Y REGLAMENTOS TÉCNICOS (OBLIGARTORIO).......... 22

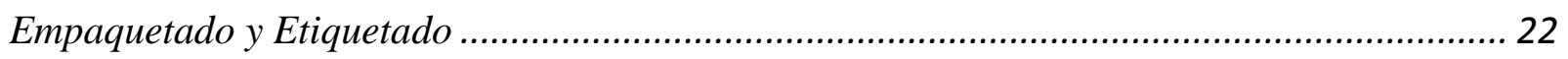

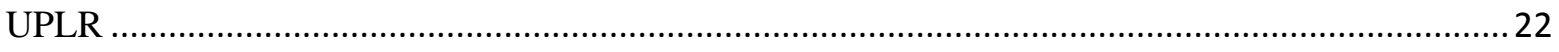

Tóxicos en la Legislación de Empaquetado ................................................................................ 23

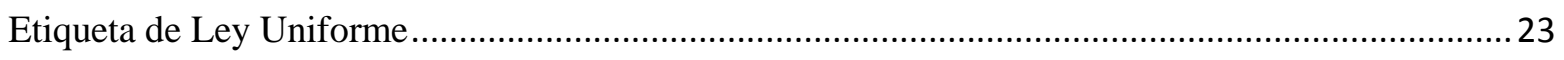

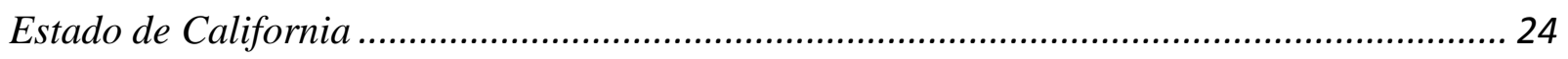

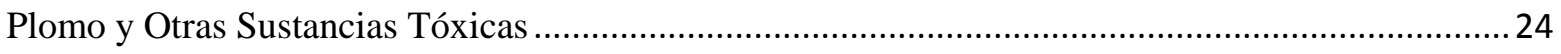

Reglamentos para Productos de Consumo más Seguros................................................................ 24

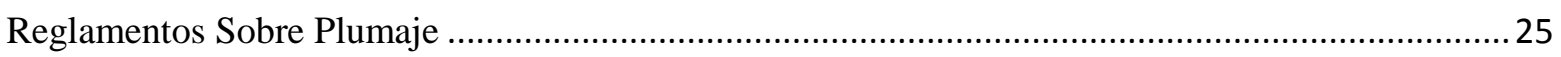

Inflamabilidad de Mobiliario Tapizado y Prendas de Cama ...........................................................25

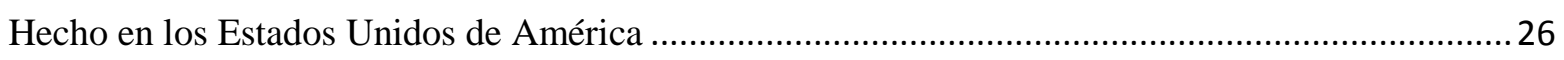

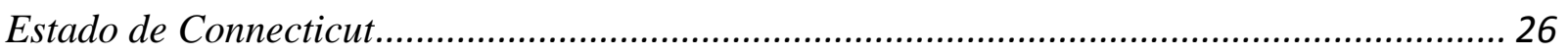

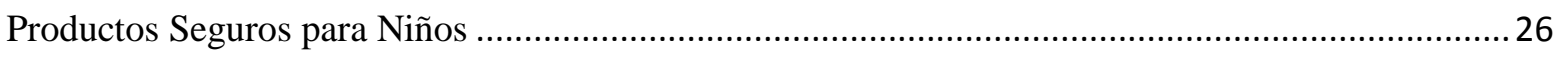

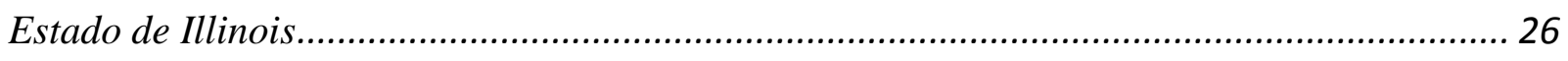

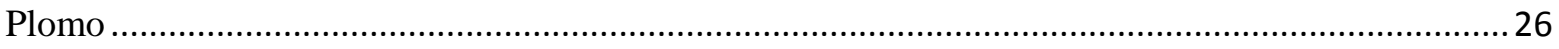

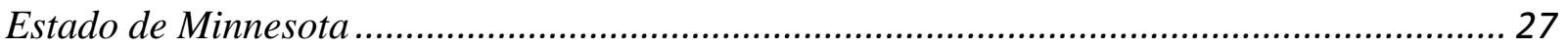

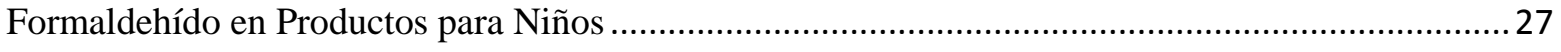

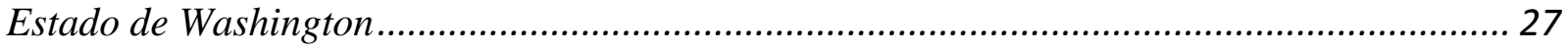

Plomo, Cadmio, y Ftalatos en Productos para Niños ....................................................................... 27

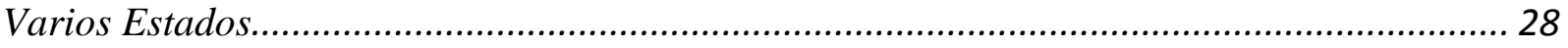


Reglamentos sobre Retardantes de Llama .............................................................................. 28

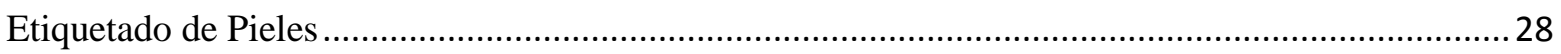

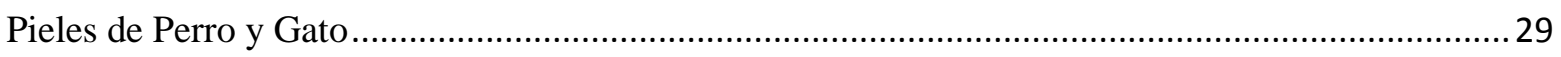

Químicos de Preocupación............................................................................................................... 29

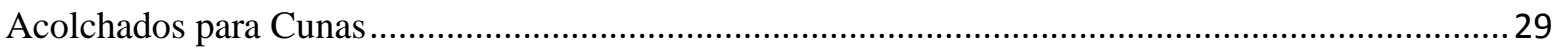

GENERALIDADES DEL MARCO DE NORMAS VOLUNTARIAS DE LOS ESTADOS UNIDOS ................ 29

ORGANIZACIONES DESARROLLADORAS DE NORMAS (SDOS).............................. 30

Asociación Americana de Químicos y Coloristas Textiles (AATCC) .................................. 30

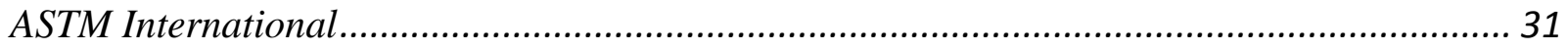

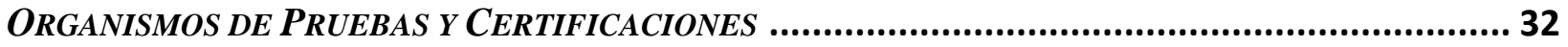

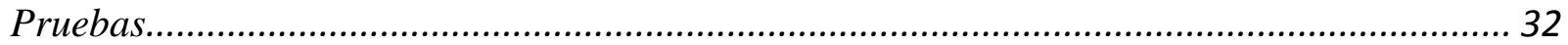

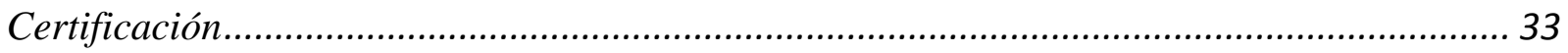

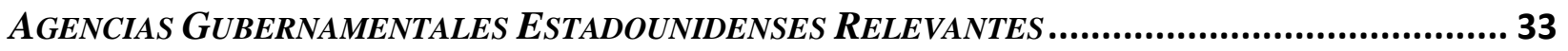

Oficina de Aduanas y Protección Fronteriza Estadounidense (CBP) .................................. 33

Comisión de Seguridad de Productos del Consumidor de Estados Unidos (CPSC)............... 33

Agencia de Protección Ambiental (EPA) ..................................................................... 34

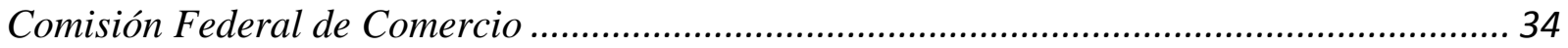

Departamento de Agricultura de los Estados Unidos....................................................... 34

DAtos de la INDUStria y El MERCADo ESTADounidenSE DE PRENDAS DE VESTIR Y TEXTILES

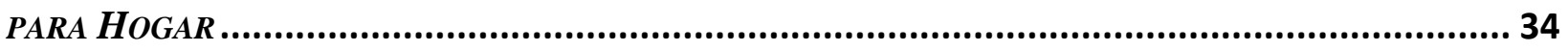

Asociaciones Comerciales de la Industria ..................................................................... 34

Datos del Mercado de Prendas de Vestir y Textiles para el Hogar ...................................... 35 


\section{Guía Estadounidense}

\section{para el Cumplimiento de Requerimientos para Textiles de Línea Hogar y de Prendas de Vestir}

\section{CÓMO USAR ESTA GUÍA}

- Los reglamentos son obligatorios

- Las normas son voluntarias (a menos que se "Incluyan por Referencia" en un reglamento)

- Los lineamientos pueden ser voluntarios (pero por lo general son normas industriales de facto)

- Los textos resaltados en "rojo" son requerimientos obligatorios

- Los textos resaltados en "azul" indican un vínculo a un sitio o página web, o a un documento en la red.

\section{ALCANCE}

La presente guía trata sobre prendas de vestir, incluyendo prendas para niños y textiles para línea de hogar. No incluye otros textiles, como bolsas para dormir, carpas, artículos deportivos, u otros productos que no pertenezcan a la categoría de línea de hogar que contengan o estén hechos de materiales textiles.

\section{GENERALIDADES DEL MARCO REgLAMENTARIO FEDERAL DE LOS ESTADOS UNIDOS}

Una vez el Congreso haya proclamado una ley, la agencia federal correspondiente (por ejemplo, la Comisión de Seguridad de Productos del Consumidor, la Comisión Federal de Comercio, La Administración Nacional de Seguridad del Tráfico en las Carreteras, y demás) podrá crear los reglamentos que implementen dicha ley. Antes de que dichos reglamentos se puedan adoptar, la agencia federal correspondiente normalmente emitirá una Notificación sobre Legislación Propuesta (NPRM, siglas en inglés) para solicitar comentarios públicos sobre dichas reglas propuestas. Para que haya ocasión de comentarios públicos, la agencia federal correspondiente debe emitir reglamentos en borrador o "Reglas Propuestas" que se publican en el Registro Federal y como notificación de Obstáculos Técnicos al Comercio de la Organización Mundial de Comercio (OTC OMC). La agencia revisa los comentarios y luego puede emitir una "Regla Final" que también se publica en el Registro Federal y, luego, se publica de manera anual en el Código de Reglamentos Federales (CFR). Al tiempo, el decreto habilitante, las leyes [publicadas en el Código de los Estados Unidos (USC) una vez se aprueben] y los reglamentos finales (publicados en el $(F R$ ) brindan un marco para la implementación y cumplimiento de la mayoría de las leyes federales en los Estados Unidos. 


\section{AUtORIDADES REGULADORAS FEDERALES Y REGLAMENTOS TÉCNICOS (OBLIGATORIOS)}

Varias agencias federales estadounidenses administran los reglamentos relacionados con prendas de vestir y textiles.

\begin{tabular}{|l|l|}
\hline Agencia & Alcance \\
\hline $\begin{array}{l}\text { Comisión de Seguridad de Productos del } \\
\text { Consumidor (CPSC) }\end{array}$ & $\begin{array}{l}\text { Inflamabilidad; productos para niños; } \\
\text { sustancias peligrosas }\end{array}$ \\
\hline $\begin{array}{l}\text { Oficina de Aduanas y Protección Fronteriza } \\
\text { (CBP) }\end{array}$ & $\begin{array}{l}\text { País de origen para la mayoría de productos } \\
\text { importados }\end{array}$ \\
\hline Agencia de Protección Ambiental (EPA) & Pesticidas; Sustancias tóxicas \\
\hline Comisión Federal de Comercio (FTC) & $\begin{array}{l}\text { Etiquetado (etiqueta de cuidado, etiquetado } \\
\text { de contenido de fibra, etiquetado ambiental, } \\
\text { etiquetado de país de origen, publicidad) }\end{array}$ \\
\hline $\begin{array}{l}\text { Departamento de Agricultura de los Estados } \\
\text { Unidos (USDA) }\end{array}$ & Contenidos ecológicos \\
\hline
\end{tabular}

\section{Comisión de Seguridad de Productos del Consumidor (CPSC)}

\section{Ley de Seguridad de Productos de Consumo (CPSA)}

Título 15, Código de los Estados Unidos, Capítulo 47, Secciones 2051-2089

La Ley de Seguridad de Productos de Consumo, en vigor desde octubre 27 de 1972, se promulgó para establecer la Comisión de Seguridad de Productos del Consumidor y define su autoridad con el propósito de proteger al público contra riesgos no razonables de lesión relacionados con productos de consumo; ayudar a los consumidores en la evaluación de la seguridad comparativa de los productos de consumo, desarrollando normas de seguridad uniformes para productos de consumo; y promoviendo la investigación sobre las causas y la prevención de muertes, enfermedades y lesiones relacionadas con el uso de productos.

\section{Ley de Mejoramiento de la Seguridad de Productos de Consumo de 2008 (CPSIA)}

Ley Pública 110-314, agosto 14 de 2008

En agosto 14 de 2008, el Presidente Obama firmó la Ley Pública 110-314 (Ley de Mejoramiento de la Seguridad de Productos de Consumo de 2008). En agosto 12 de 2011, firmó las modificaciones a dicha Ley, Ley Pública 112-28, agosto 12 de 2011. La Ley le proveyó a la CPSC herramientas nuevas y significativas de reglamentación como parte de la modificación y el mejoramiento de varios estatutos de la CPSC, incluyendo la Ley de Seguridad de Productos de Consumo. 


\section{Únicamente Prendas para Niños y Prendas de Dormir}

La Ley de Mejora de la Seguridad de Productos de Consumo (CPSIA, siglas en inglés) promulgada en 2008, regula las sustancias específicas en los productos para niños, incluyendo prendas para niños y prendas de dormir. La CPSIA establece los límites para el contenido de plomo y ftalatos en productos para niños. Los productos para niños se definen como productos de consumo diseñados o fabricados principalmente para niños de 12 años de edad o menos.

Con respecto a las prendas para niños, la Sección 101(a) de la CPSIA restringe los productos para niños, incluyendo prendas para niños y prendas de dormir, a un límite de contenido de plomo de 100 partes por millón (ppm). Adicionalmente, el uso de pintura o revestimiento de superficie similar en prendas para niños y prendas de dormir no debe exceder el límite de contenido de plomo de 90 ppm. La CPSC recientemente revisó la norma 16 CFR 1500.91(d)(7) para aclarar que la Comisión ha determinado que los textiles que tengan tratamientos y aplicaciones que consistan totalmente en colorantes, no excedan los límites de contenido de plomo y que no se encuentren sujetos a los requerimientos de prueba por parte de un tercero para productos para niños, siempre y cuando dichos materiales no hayan tenido ningún tipo de tratamiento o se les haya adulterado con materiales que pudieran agregar plomo.

Además, la Sección 108 de la CPSIA reza que los juguetes para niños y artículos de cuidado para niños no pueden contener más del $0.1 \%$ de seis ftalatos - los límites para DEHP, DBP, BBP aplican tanto para juguetes como para artículos de cuidado para niños, mientras que los límites para DINP, DIDP, y DnOP aplican únicamente a juguetes que se pueden llevar a la boca y estén fabricados para niños de 3 años de edad o menos. Aunque las prendas para niños no necesitan tener certificación para este requerimiento, las prendas de dormir para niños o los baberos (artículo de cuidado para niños) diseñados para niños de 3 años de edad o menos y cualquier producto textil para niños que se utilice para jugar (juguete) debe estar certificado para los requerimientos de ftalatos.

\section{Certificados y Pruebas Obligatorias de Terceros}

La Sección 102 de la CPSIA exige que todos los fabricantes o importadores de todos los productos de consumo que estén sujetos a las reglas de seguridad de productos de consumo establecidas por la CPSC emitan un certificado general de conformidad según las pruebas que se le hagan a sus productos en el que diga que el producto cumple con la norma, regulación o prohibición aplicable. El certificado debe acompañar al producto y debe entregársele al minorista o al distribuidor. La Sección 102 también exige que los fabricantes o los importadores de productos para niños (productos diseñados y pensados inicialmente para niños de 12 años de edad o menos) certifiquen que los productos cumplan con todas las normas de seguridad de los productos, emitiendo un certificado de producto para niños sustentado con pruebas llevadas a cabo por laboratorios externos de pruebas aceptados por la CPSC que hayan sido acreditados. La CPSC también establece reglamentos que tienen que ver con los Certificados de Cumplimiento; estos se pueden encontrar en la 16 CFR 1110. 
Todo fabricante de un producto que no sea para niños (y el distribuidor de marcas blancas para dicho producto, si dicho producto lleva una etiqueta de marca propia) está sujeto a los reglamentos de la CPSC para:

- Tapetes y alfombras (16 CFR 1630 y $\underline{1631})$

- Película de vinilo (16 CFR 1611)

- Indumentaria (16 CFR 1610)

Para información detallada, refiérase a los ítems de la CPSC en cuanto a: Pruebas y Certificaciones y Preguntas Frecuentes - Certificación y Pruebas por Agentes Externos

\section{Etiquetas de Rastreo en Prendas para Niños}

Se exigen etiquetas de rastreo para todos los productos diseñados y pensados para niños de 12 años de edad y menos, incluyendo prendas para niños. La etiqueta de rastreo debe colocársele al producto (hasta el punto que sea práctico) y a su empaque, de manera visible y legible, y debe brindar cierta información básica de identificación, incluyendo:

- Nombre del fabricante o distribuidor de marcas blancas;

- Ubicación y fecha de producción del producto;

- Información detallada sobre el proceso de fabricación, como número de lote o de producción, u otras características de identificación; y

- Cualquier otra información que facilite determinar la fuente específica del producto.

Para información detallada, refiérase a los ítems de la CPSC en cuanto a:

$\underline{\text { Requerimientos de etiqueta de rastreo de productos para niños }}$

\section{Sillas Suaves para Bebés y Niños Pequeños}

La Sección 104 de la CSPIA exigía que la CPSC promulgara normas de seguridad de productos para consumidores en cuanto productos durables para bebés y niños pequeños. Como respuesta a lo anterior, la CPSC ha emitido una regla final, 16 CFR 1226 Norma de Seguridad para sillas suaves para bebés y niños pequeños.

Toda silla suave para bebés y niños pequeños debe cumplir con todas las disposiciones aplicables de la ASTM F2236-14, que se han incluido como referencia. La norma incluye los requerimientos generales que deben cumplir los productos, así como métodos de pruebas específicos para asegurarse del cumplimiento con los requerimientos generales, que incluyen:

- restricciones a puntas o bordes filosos, según la 16 CFR 1500.48 y .49;

- restricciones a partes pequeñas, según la 16 CFR 1501;

- restricciones a plomo en la pintura, como se establece en 16 CFR 1303; 
- requerimientos para dispositivos de cierre y enclavamiento;

- requerimientos para etiquetas permanentes de precaución;

- restricciones a la inflamabilidad, como se establece en 16 CFR 1610;

- requerimientos para accesorios de juguetes, como se establece en ASTM F 963;

- requerimientos sobre el desempeño;

- requerimientos para las etiquetas de precaución.

Adicionalmente, bajo la Sección 14 de la CPSA, las sillas suaves para bebés y niños pequeños también se encuentran sujetas a requerimientos de pruebas y certificaciones por parte de agentes externos.

\section{Cordones en Prendas Infantiles para la Parte Superior del Cuerpo}

En febrero de 1996, la CPSC emitió lineamientos que se incorporaron en una norma voluntaria de la industria para prevenir el estrangulamiento de niños debido a los cordones de las prendas para la parte superior del cuerpo. En julio de 2011, la CPSC aprobó una regla federal de seguridad para los cordones en prendas infantiles para la parte superior del cuerpo. Las prendas infantiles para la parte superior del cuerpo en las tallas $2 \mathrm{~T}-16$ deben cumplir con la ASTM F1816-97, Norma de Especificación de Seguridad para los Cordones en Prendas Infantiles para la Parte Superior del Cuerpo, aprobada en junio 10 de 1997, publicada en agosto de 1998 (incluida como referencia en 16 CFR 1120.3 (b)), o de lo contrario dichas prendas se considerarán como producto de riesgo importante.

\section{Ley de Telas Inflamables}

Título 15, Código de los Estados Unidos, Capítulo 25, Secciones 1191-1204

La Ley de Telas Inflamables prohíbe a los fabricantes que ofrezcan, vendan, pongan a la venta, importen a los Estados Unidos, introduzcan, entreguen para introducir al mercado, transporten, o hagan que se transporte, en el comercio, o en la venta o entrega después de la venta o al envío al comercio de todo producto, tela, o material relacionado que no cumpla con las normas o reglamentos de inflamabilidad emitidas bajo dicha Ley. Estas normas se han establecido para los efectos correspondientes de inflamabilidad de textiles para prendas, películas de vinilo (utilizadas en prendas de vestir), alfombras y tapetes, prendas de dormir para niños, y colchones y protectores para colchón.

Esta ley aplica a todo tipo de tela que se defina en la Ley como "todo material (excepto fibra, filamentos, o hilo diferente a los de venta al por menor) tejidos, tejidos de punto, fieltros, o producidos de otra manera o en combinación con cualquier fibra, natural o sintética, película, o sustituto de los mismos cuyo propósito sea el uso o que se pueda de manera razonable esperar su uso, en cualquier artículo de prenda para vestir o equipamiento interior."

Para información detallada, refiérase a los ítems de la CPSC en cuanto a: Ley de Telas Inflamables 


\title{
Inflamabilidad de Prendas de Vestir
}

La norma 16 CFR 1610 - Norma para la Inflamabilidad de Textiles de Prendas de Vestir ofrece métodos para probar la inflamabilidad de las Prendas de Vestir y los textiles diseñados para usarse en prendas de vestir al clasificar las telas en tres clases de inflamabilidad según su velocidad de consumo por el fuego. Esta norma mínima especifica que los textiles utilizados en las prendas de vestir deben cumplir con los requerimientos clase 1 o 2 de inflamabilidad. Los textiles Clase 3 , las telas más peligrosamente inflamables, no son aptas para su uso en prendas de vestir debido a sus características de quemado rápido e intenso.

\author{
Para información detallada, refiérase a los ítems de la CPSC en cuanto a: \\ Resumen Reglamentario de la Ley de Telas Inflamables y \\ Manual de Pruebas de Laboratorio para la norma 16 CFR Parte 1610: Norma para la \\ Inflamabilidad de Textiles de Prendas de Vestir
}

\section{Inflamabilidad de Película de Vinilo}

Las Películas de Vinilo utilizadas en prendas de vestir debe cumplir con la norma 16 CFR 1611 - Norma para la Inflamabilidad de Película de Vinilo. La norma aplica a todas las partes expuestas o sin cubrir de las prendas de vestir fabricadas con plástico, caucho o cualquier otro sintético o película natural o lámina que no sea rígida y no tenga soporte, incluyendo materiales transparentes, translucientes, y opacos, ya bien sean planos, repujados, moldeados o cuya superficie haya sido tratada de alguna otra manera, que se encuentre en forma o condición lista para su uso en prendas de vestir, y que incluya películas o láminas que excedan los 10 milímetros $(0.254 \mathrm{~mm})$ de grosor.

\section{Inflamabilidad de las Prendas de Dormir para Niños}

La norma 16 CFR 1615 Norma para la Inflamabilidad de prendas de dormir para niños: tallas 0 a 6X y la norma 16 CFR 1616 Norma para la Inflamabilidad de prendas de dormir para niños: tallas $\underline{7}$ a 14 establece requerimientos obligatorios de inflamabilidad para las prendas de dormir para niños. Las prendas de dormir para niños deben ser resistente al fuego y se deben apagar por sí mismas cuando se expongan a una fuente pequeña de ignición. Las reglas incluyen todo tipo de prendas de dormir para niños entre las tallas para 9 meses hasta la talla 14. La tela, las costuras, el corte, y las prendas deben aprobar ciertas pruebas de inflamabilidad o deben ajustarse según las dimensiones especificadas.

Todas las prendas ceñidas deben cumplir con los requerimientos de etiquetado en las Normas, 16 CFR 1615.1(0) (10), (11) y 16 CFR 1616.2(o) (10) y (11). Estas Normas exigen una etiqueta colgable que debe cumplir con el tamaño, fuente, texto y color de fondo especificados, así como con una etiqueta de cuello que también debe cumplir con el texto, diseño, ubicación y delineo de ajuste para las prendas de dormir para niños. Las prendas ceñidas de dormir deben 
llevar la etiqueta de prenda especificada (Figura 1) y la etiqueta colgable (Figura 2) a menos de que la prenda se venda empacada, en cuyo caso el empaque deberá portar la etiqueta amarilla.

Las prendas ceñidas de dormir deben cumplir con todos los requerimientos de Inflamabilidad de textiles para prendas (16 CFR 1610) o Película de Vinilo (si aplica).

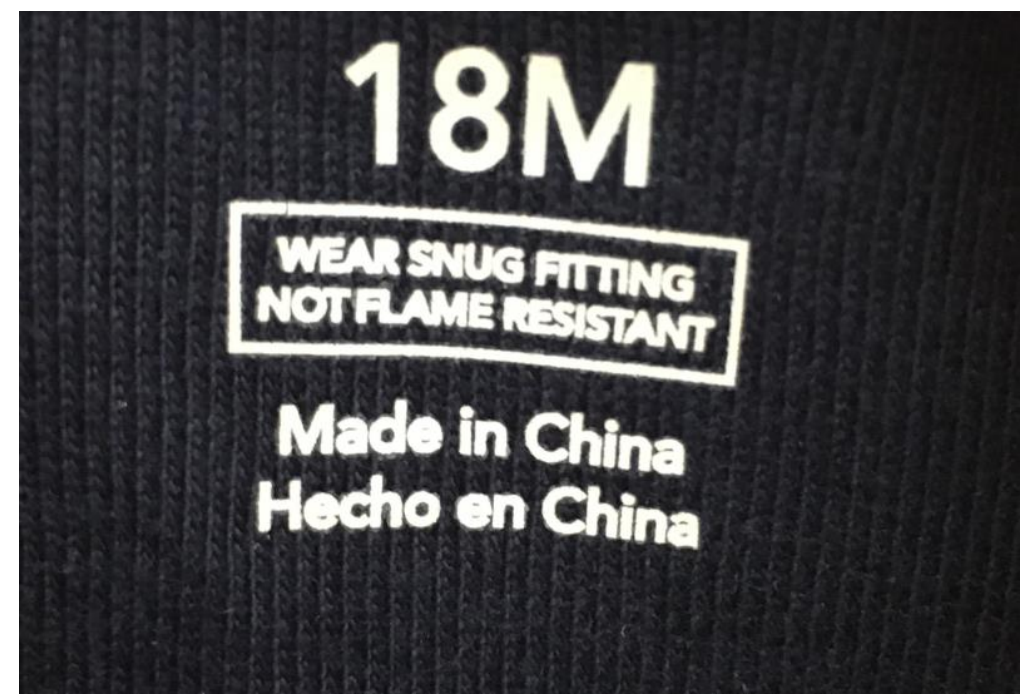

Figura 1 - Las prendas ceñidas de dormir también deben llevar una etiqueta justo bajo la talla ubicada en el centro de la parte trasera de la prenda.

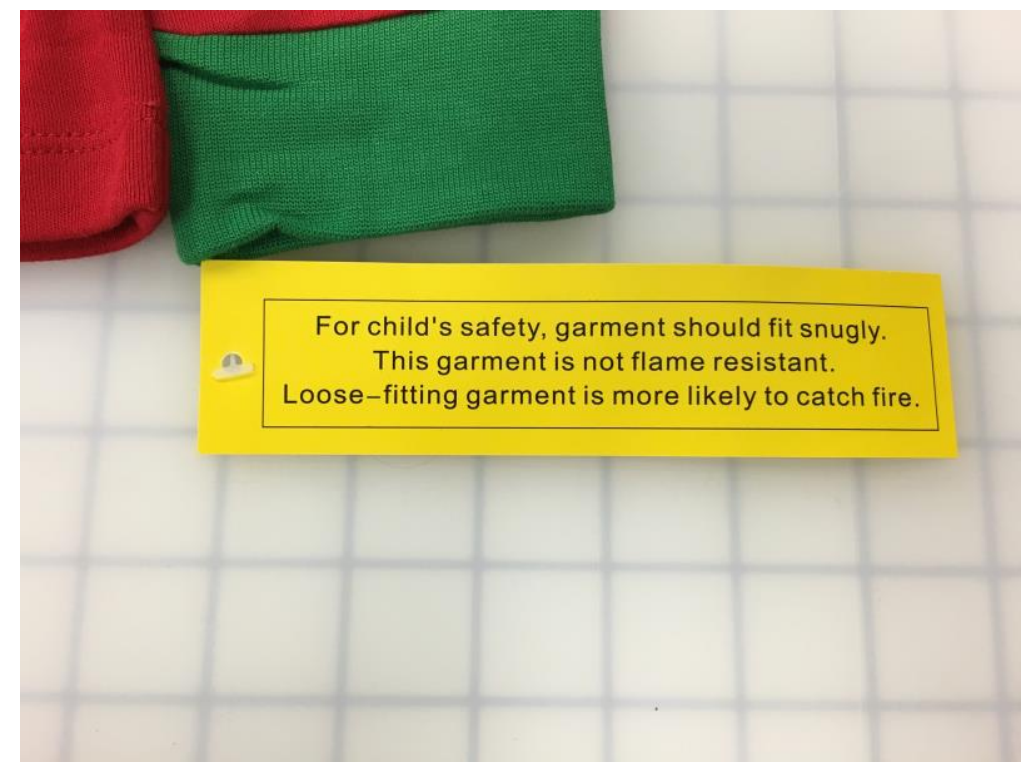

Figure2: Las prendas ceñidas de dormir deben llevar una etiqueta colgable específica sin ninguna otra información o deben llevar una etiqueta en el empaque 
Para información detallada, refiérase a los ítems de la CPSC en cuanto a:

Carta de Política y Posición para las Prendas de Dormir y las Prendas de Entrecasa

y Manual de Pruebas de Inflamabilidad de Prendas de Dormir para Niños

\section{Inflamabilidad de Alfombras y Tapetes}

Las alfombras y tapetes deben cumplir con los requerimientos de Inflamabilidad según aplique en la norma 16 CFR 1630: Norma para la Inflamabilidad de Superficies de Alfombras $y$ Tapetes o 16 CFR 1631: Norma para la Inflamabilidad de Superficies de Alfombras y Tapetes Pequeños. Estas normas ofrecen métodos de pruebas que determinan la inflamabilidad de la superficie de alfombras y tapetes cuando se exponen a una fuente pequeña de ignición bajo condiciones de protección contra corrientes de aire prescritas cuidadosamente. Aplican a todos los tipos de alfombras y tapetes utilizados como material de cobertura de pisos sin importar su método de fabricación o si están hechos de fibras o películas naturales o sintéticas, o combinaciones o sustitutos de las mismas.

Si la alfombra o tapete ha tenido un tratamiento retardante de fuego o si están fabricados con fibras que han pasado por un tratamiento retardante de fuego, deberán etiquetarse con la letra " $T$ " de manera legible y visible en la etiqueta y/o factura o cualquier otro documento relacionado con la alfombra o tapete si se instala comercialmente. Las alfombras y tapetes pequeños que no cumplan con el criterio de aceptación de la norma se etiquetarán permanentemente con el siguiente enunciado:

INFLAMABLE (NO CUMPLE CON LA NORMA FF 2-70 DEL DEPARTAMENTO ESTADOUNIDENSE DE COMERCIO): NO USARSE EN FUENTES CERCANAS DE IGNICIÓN

\section{Inflamabilidad de Juegos para Colchón, Colchones, y Protectores para Colchón}

La norma 16 CFR 1632: Norma para la Inflamabilidad de Colchones y Protectores para Colchón y la norma 16 CFR 1633: Norma para la Inflamabilidad (Llama abierta) de Juegos para Colchón establecen los requerimientos de Inflamabilidad para colchones y protectores para colchón y Juegos para Colchón, respectivamente. La norma 16 CFR 1632 exige diseños de prototipos de colchones y protectores para colchón, antes de su venta en el comercio o su introducción al mercado, para que cumplan con los requerimientos de inflamabilidad de esta norma. La norma prescribe una prueba para determinar la resistencia a la ignición de un colchón o un protector de colchón al ser expuesto a un cigarrillo encendido.

Además, todo colchón o protector de colchón debe estar permanentemente etiquetado con la ciudad y el estado, así como con el mes y año de fabricación. Los protectores para colchón que hayan sido tratados con un químico retardante de llamas deben igualmente etiquetarse de manera vistosa con la letra " $\mathrm{T}$ " $\mathrm{y}$ deben tener instrucciones sobre cómo protegerlos contra químicos que reduzcan sus propiedades resistentes al fuego. 
La norma 16 CFR 1633 establece los requerimientos de Inflamabilidad que todos los diseños de prototipo de Juegos para Colchón deben cumplir antes de su venta o su introducción al mercado. El método de prueba establecido en esta regulación mide el desempeño de inflamabilidad (características de respuesta a la prueba de fuego) de un prototipo de colchón (o juego de colchón) al exponerlo a una fuente especificada de ignición y permitiendo que se queme libremente en condiciones ambientales controladas y de buena ventilación. Todos los juegos para colchón deben cumplir con los requerimientos de desempeño de inflamabilidad de la presente regulación.

Cada colchón o juego de colchón deberá llevar una o varias etiquetas permanentes, visibles y legibles que contengan la siguiente información (y no otra información) en inglés:

- Nombre del fabricante, o para los juegos para colchón importados, el nombre del fabricante extranjero e importador.

- Para los juegos para colchón producidos en los Estados Unidos, la dirección física completa del fabricante.

- Para los juegos para colchón importados, la dirección completa del fabricante extranjero, incluyendo el país y la dirección física completa del importador o su ubicación en los Estados Unidos en donde se encuentran los registros solicitados en caso de que sea diferente a la dirección del importador.

- Mes y año de fabricación.

- Identificación de modelo.

- Número de identificación del prototipo para el juego de colchón. Una declaración que identifique si el fabricante diseñó el colchón para venderse solo o con su respectiva base.

- Para colchones diseñados para venderse solos sin una base, la etiqueta debe decir "ESTE COLCHÓN SE DISEÑó PARA USARSE SIN BASE."

- Para colchones diseñados para venderse con una base, la etiqueta debe decir "ESTE COLCHÓN SE DISEÑÓ PARA USARSE CON BASE(S): < ID de la base >."

- Para colchones diseñados para venderse tanto solos como con base, la etiqueta debe decir "ESTE COLCHÓN SE DISEÑÓ PARA USARSE CON O SIN BASE(S): < ID de la base $>$."

- Certificado en la etiqueta de que el colchón cumple con esta norma.

- Para colchones diseñados para venderse sin una base, un certificado que diga “Este colchón cumple los requerimientos de la norma 16 CFR Parte 1633 (Norma Federal de Inflamabilidad (Ilama abierta) para Colchones) cuando se utiliza sin base."

- Para colchones diseñados para venderse con una base, un certificado que diga "Este colchón cumple con los requerimientos de la norma 16 CFR Parte 1633 (Norma Federal de Inflamabilidad (Ilama abierta) para Colchones) cuando se utiliza con una base < ID >." Dicha(s) base(s) deben estar claramente 
identificadas mediante un nombre sencillo y distinto y/o número en la etiqueta del colchón.

- Para colchones diseñados para venderse tanto solos como con base, un certificado que diga "Este colchón cumple con los requerimientos de la norma 16 CFR Parte 1633 (Norma Federal de Inflamabilidad (llama abierta) para Colchones) cuando se utiliza con o sin base(s) < ID >." Dicha(s) base(s) deben estar claramente identificadas mediante un nombre sencillo y distinto y/o número en la etiqueta del colchón.

\section{Para información detallada, refiérase a los ítems de la CPSC en cuanto a:}

Manual de Pruebas

76 FR 59014 -- 16 CFR Parte 1632 -- Norma para la Inflamabilidad de Colchones y Protectores para Colchón; Modificación Técnica -- 23 de septiembre de 2011 (Nota: 1632.4(a)(2) - fuente de ignición - en revisión) y

75 FR 72944 -- 16 CFR Partes 1632 y 1633 - Pruebas de Terceros para Ciertos Productos para Niños; Colchones, Protectores para Colchón, y/o Juegos para Colchón: Revisiones a los Términos de Aceptación de las Certificaciones de Productos para Niños Según las Pruebas del Organismo de Evaluación de Conformidad de Terceros Antes a la Aceptación de Acreditación de la Comisión -- 29 de noviembre de 2010

\section{Ley Federal de Sustancias Peligrosas (FHSA)}

Título 15, Código de los Estados Unidos, Capítulo 30, Secciones 1261-1278 16 CFR 1500, Ley Federal de Sustancias Peligrosas (FHSA)

Requerimientos de los reglamentos FHSA establecidos para sustancias domésticas peligrosas en productos. La FHSA exige que las sustancias domésticas que cumplan la definición dada al término peligroso (como se define en la Ley) lleven etiquetado de prevención para advertir al consumidor sobre el (los) peligro(s) relacionado(s) con el uso del producto, que le permitiera al consumidor usar y almacenar de manera segura el producto, incluyendo instrucciones de primeros auxilios, si aplica, y un aviso que diga "Mantener fuera del alcance de los niños." Si se debe o no etiquetar el producto depende de su formulación y de la probabilidad de que los consumidores estén expuestos a cualquier peligro que presente en su uso acostumbrado de manera razonable y previsible, lo que incluye ingesta por parte de niños. La FHSA también define como productos peligrosos prohibidos aquellos que hayan sido diseñados para niños y que representen un riesgo eléctrico, mecánico, o térmico, con algunas excepciones. La Ley también permite que la Comisión de Seguridad de Productos del Consumidor prohíba mediante potestad reglamentaria ciertos productos que sean muy peligrosos o que la naturaleza del peligro sea tal que los requerimientos del etiquetado de prevención no sean adecuados para proteger a los consumidores. 


\section{Puntas y Bordes Filosos en Productos para Niños}

La norma 16 CFR 1500.48 "Requerimientos técnicos para determinar puntas filosas en juguetes y otros artículos diseñados para niños menores de 8 años de edad" establece el método de prueba para determinar si una punta filosa, expuesta en uso normal o mediante daño o abuso razonable y previsible, en juguetes y otros artículos diseñados para el uso de niños menores a 8 años de edad presenta un riesgo potencial de lesión mediante punción o laceración según la Sección 2(s) de la Ley Federal de Sustancias Peligrosas.

De igual manera la norma 16 CFR 1500.49 "Requerimientos técnicos para determinar si el borde filoso en metal o en vidrio en juguetes y otros artículos diseñados para niños menores a 8 años de edad" proporciona el método de prueba para bordes filosos utilizado para determinar si los bordes de metal o de vidrio, expuestos en el uso normal o como resultado de su daño o abuso previsible, en juguetes y otros artículos diseñados para niños menores de 8 años de edad presentan un riesgo potencial de lesión mediante laceración o avulsión según la Sección 2(s) de la Ley Federal de Sustancias Peligrosas. Las prendas para niños y artículos textiles técnicamente no hacen parte de este alcance; sin embargo, los textiles y las prendas para niños que contienen puntas y bordes filosos se pueden considerar como productos peligrosos y la CPSC solicitará el retiro voluntario del producto del mercado por parte del fabricante o emitirá una orden de retiro obligatoria del producto.

Para información detallada, refiérase a los ítems de la CPSC en cuanto a: Resumen Reglamentario para Requerimientos según la Ley Federal de Sustancias Peligrosas: Requerimientos de Etiquetado y Prohibición para Sustancias Químicas y Otras Sustancias Peligrosas

\section{Prohibición en Cojines para Bebés}

16 CFR Parte 1500.18 (a) (16) - vínculo de la información actual que prohíbe los cojines y almohadas para bebés que tengan todas las siguientes características:

- Revestimiento de tela flexible,

- Rellenos con material granular como bolitas de espumado plástico o perdigones,

- Se puede aplastar fácilmente,

- Puede amoldarse al cuerpo o a la cara de un bebé, y

- Se diseñó o promocionó para su uso por parte de niños menores de un año edad.

\section{Norma Sobre Cubiertas de Ventanas y Cuerdas}

El personal de la CPSC trabaja en la actualidad con la Asociación de Fabricantes de Cubiertas para Ventanas (WCMA) para desarrollar los requerimientos de desempeño y los métodos de prueba para estudiar los riesgos de estrangulación relacionados con productos de cubiertas para ventanas que utilicen cuerdas y para estandarizar las precauciones respecto a los peligros relacionados con los bucles de las cuerdas internas, enfocándose en la necesidad para que se hagan los ajustes necesarios de los dispositivos de detención de la cuerda interna. La norma 
voluntaria del "Instituto Nacional Estadounidense de Estándares para la Seguridad de Productos de Cubierta y Cuerdas para Ventanas" (ANSI/WCMA A.100.1) proporciona los requerimientos para los productos de cubierta que abordan los peligros de estrangulación relacionados con bucles continuos de cuerdas, cuerdas internas, y juntas de cuerdas. Aunque esta norma es voluntaria, la CPSC puede y ha solicitado el retiro del mercado de cubiertas para ventanas que presentan riesgo de estrangulación.

Para información detallada, refiérase a los ítems de la CPSC en cuanto a: Cuerdas de Persianas para Ventana

\section{Reglamentos Pendientes de Notificación}

La CPSC publicó recientemente en el Registro Federal las siguientes Notificaciones sobre Legislación Propuestas (NPRM). Cada notificación brinda especificaciones respecto a las modificaciones que se estén considerando y solicita que se hagan comentarios. Ver:

Notificación sobre Legislación Propuesta: Prohibición de Artículos de Cuidado y Juguetes para Niños que Contengan Ftalatos Especificados (diciembre 30 de 2014)

Notificación sobre Legislación Propuesta: Norma de Seguridad para Cangureras (Julio 23 de 2014)

Notificación sobre Legislación Propuesta: Certificados de Cumplimiento (mayo 13 de 2013)

Notificación Avanzada sobre Legislación Propuesta: Cubiertas para Ventanas con Cuerdas; Solicitud de Comentarios e Información (1/16/2015)

\section{Oficina de Aduanas y Protección Fronteriza (CBP)}

\section{País de origen: Marcado de Artículos Importados y Contenedores}

Título 19, Código de los Estados Unidos, Capítulo 4, La Sección 1304

Todos los productos importados a los Estados Unidos deben cumplir con los reglamentos 19 CFR 134, Marcado de País de Origen. Tales reglamentos requieren que cada artículo de origen extranjero (o su contenedor) importado a los Estados Unidos se encuentre marcado en un lugar visible de manera legible, indeleble y permanente tanto como lo permita la naturaleza del artículo (o contenedor), y de esa manera indicar al comprador final en los Estados Unidos el nombre en inglés del país de origen del artículo al momento de la importación.

Para información más detallada, ver lo pertinente a la CBP en cuanto a:

Terminología y Métodos de Marcado de País de Origen en Importaciones a Estados Unidos 


\title{
Agencia de Protección Ambiental (EPA)
}

\section{Prendas Antimicrobianas y Textiles para el Hogar: Ley Federal para Insecticidas, Fungicidas y Venenos para Roedores (FIFRA)}

Título 7, Código de los Estados Unidos, Capítulo 6, Sección 136

Esta Ley proporciona la regulación federal para la distribución, venta y uso de pesticidas para proteger la salud humana y el ambiente. Los productos que matan o repelen bacterias o gérmenes se consideran pesticidas y se deben registrar ante la EPA antes de comenzar su distribución o venta. La EPA no registra un pesticida a menos que haya sido probado y se compruebe que no representa ningún riesgo no razonable al momento de utilizarlo según las sus instrucciones. Lo anterior incluye pesticidas utilizados en prendas de vestir o textiles para ofrecer protección antimicrobiana u otras características pesticidas.

La FIFRA no permite a las empresas que anuncien pesticidas que no afecten la salud pública de cualquier producto que se distribuya o venda a menos que dicho producto haya sido aprobado y registrado por la EPA o esté amparado por una excepción de registro. La EPA entablará acciones legales en contra de aquellas empresas que realicen tales anuncios.

\author{
Para información más detallada, ver los reglamentos de la EPA respecto a: \\ Ley Federal para Insecticidas, Fungicidas y Venenos para Roedores (FIFRA), \\ Productos de consumo Tratados con Pesticidas, \\ Notificaciones de Registro de Pesticidas por Año, \\ Registro de Pesticidas, y \\ Etiquetas de Productos Pesticidas
}

\section{Ley de Control de Sustancias Tóxicas (TSCA)}

La Ley de Control de Sustancias Tóxicas de 1976 (15 USC 2601-2692) le proporciona a la EPA la autoridad para solicitar informes, gestión de archivos, requerimientos de pruebas y restricciones relacionadas con sustancias químicas y/o mezclas. Ciertas sustancias por lo general están excluidas de la TSCA, incluyendo, entre otras, alimentos, medicinas, cosméticos y pesticidas.

La EPA ha promulgado una nueva regla de uso significativo (SNUR) para el hexabromociclododecano y el hexabromociclododecano 1, 2, 5, 6, 9, 10 (HBCD) como retardante de llama en textiles de consumo (diferentes a los que se utilizan en vehículos automotores). La regla, efectiva a partir de noviembre 23 de 2015, se adicionará a la Sección 40 CFR 721 para solicitarles a las personas que deseen fabricar (incluyendo la importación) o procesar estos químicos para el uso mencionado anteriormente que notifiquen a la EPA con al menos 90 días de anterioridad al comienzo de dicha actividad. La notificación requerida le brindará a la EPA la oportunidad de evaluar el uso planteado y, si es adecuado, prohibir o limitar dicha actividad antes de que ocurra. La EPA también se encuentra finalizando una SNUR 
para el uso de sustancias químicas que contengan carboxilato de perfluoroalquilo de cadena larga (LCPFAC) y que se agreguen a las alfombras o se usen para tratar alfombras.

Adicionalmente, la EPA propone diseñar éteres difenílicos polibromados (PBDE), que se utilicen como retardadores de llama, y colorantes de bencidina, que se utilicen para tinturar textiles, como SNUR.

Para información más detallada, ver los reglamentos de la EPA relacionados con:

Hexabromociclododecano (HBCD),

Químicos Perfluorinados de Cadena Larga (PFCs)

Plan de Acción para PBDE, y

Plan de Acción para Colorantes de Bencidina

\section{Comisión Federal de Comercio (FTC)}

\section{Ley de la Comisión Federal de Comercio (FTC)}

Título 15, Código de los Estados Unidos, Capítulo 2, Sub Capítulo I, Secciones 41-58

La Ley de la FTC prohíbe ampliamente las acciones engañosas o injustas, así como las prácticas en o que afecten el comercio. La comisión entenderá engaño en caso de que, sea por la inclusión o exclusión de información, sea probable que:

- Se induzca a los consumidores a error actuando de manera razonable según las circunstancias, $y$

- se afecte la elección o conducta del consumidor, y por lo tanto se genere una lesión.

La Ley de la FTC le permitía a esta promulgar reglamentos con el fin de prohibir actos o prácticas engañosas o injustas.

Para información más detallada, ver lo relacionado con la FTC en cuanto a:

Recurso de Prendas de vestir y Textiles de la Oficina de Protección al Consumidor (BCP) del Centro de Negocios de la FTC

\section{Ley de Identificación de Productos de Fibra Textil}

Título 15, Código de los Estados Unidos, Capítulo 2, Sub Capítulo V, Sección 70

16 CFR 303, Reglas y Reglamentos según la Ley de Identificación de Productos de Fibra Textil La importación, fabricación, venta, puesta en venta, transporte para venta, distribución, o publicidad para cualquier producto de fibra textil que se promocione con etiquetas falsas o engañosas es ilegal y se considera un método injusto de competencia, así como una acción o práctica injusta y engañosa en el comercio bajo la Ley de la FTC. Para evitar ser considerado como marca engañosa, la Ley exige que la mayoría de productos textiles lleven una etiqueta adjunta que enliste: 
- Los nombres genéricos y porcentajes por peso de los constituyentes de las fibras del producto;

- El nombre bajo el cual el fabricante u otra empresa responsable negocia o, en lugar de los mismos, el número de identificación registrado ("Número RN") de dicha empresa; y

- El nombre del país en el que se procesó o fabricó el producto.

La Ley de Identificación de Productos de Fibra Textil también contiene disposiciones sobre publicidad y gestión de archivos.

Se requiere colocar una etiqueta a cada producto textil y, en donde se exija, a su empaque o contenedor de manera segura. Dicha etiqueta debe ser visible y debe ser lo bastante durable como para permanecer adherida al producto y su empaque durante cualquier proceso de distribución, venta, re-venta, y hasta que finalmente sea vendida o entregada al consumidor final.

Todo producto de fibra textil que tenga cuello debe llevar una etiqueta en la que se indique el país de origen y esta debe estar adherida en la parte interior, central del cuello a media distancia entre el cuello y la costura de los hombros o muy cerca a cualquier otra etiqueta que se adhiera o ponga en la parte interior central del cuello de la prenda. El contenido de fibra y el RN o nombre de la empresa se puede poner en la misma etiqueta en la que se pone el país de origen o en cualquier otra $u$ otras etiquetas visible y de fácil acceso en la parte interior o exterior de la prenda de vestir. En todos los demás productos textiles, se pondrá la información requerida en una o varias etiquetas visibles y de fácil acceso en la parte interior o exterior del producto. Siempre debe aparecer la información sobre el país de origen en la parte frontal de la etiqueta. Otra información que se requiera podrá aparecer ya bien sea en el lado frontal o al reverso de la etiqueta, siempre y cuando la información sea visible, de fácil acceso, y bien legible.

Los productos calcetines empacados no necesitan etiqueta en cada uno de los pares siempre y cuando la información solicitada se registre en la etiqueta del empaque y lo anterior aplica para todos los pares de calcetines dentro del paquete.

Los calcetines deben estar marcados en el frente de sus empaques o en las etiquetas con el nombre en inglés del país de origen. Dicho marcado se debe poner al lado de la talla. El marcado se debe realizar de forma legible, indeleble, visible, de fácil acceso para el consumidor, y de forma permanente como la naturaleza del artículo o empaque lo permita.

Lo productos que vengan empacados, como las camisetas, deben venir etiquetados sobre el producto y en el empaque, a menos que la etiqueta del producto sea claramente visible a través del empaque.

Una modificación realizada en 2014 a las Reglas para Textiles permite que las etiquetas colgables lleven el nombre genérico de las fibras, la marca, o las características de la fibra que 
no divulguen el contenido total de fibras del producto; sin embargo, si el producto textil contiene alguna otra fibra, la etiqueta colgable debe decir clara y visiblemente que no informa sobre el contenido total de fibras del producto (por ejemplo, "Esta etiqueta no divulga el contenido completo de las fibras del producto" o "Ver etiqueta interna para el contenido total de fibras del producto").

\section{Para información más detallada, vea lo relevante a los requerimientos de la FTC en cuanto a:}

Hile su Camino hacia los Requerimientos de Etiquetado según las Leyes sobre Textiles y Lana.

\section{Relleno Usado o de Segunda Mano}

16 CFR 303, Reglas Y Reglamentos Según la Ley de Identificación de Productos de Fibra Textil Todo producto tapizado, colchón, o cojín que contenga relleno que haya sido utilizado con anterioridad como relleno en cualquier otro producto tapizado, colchón o cojín debe llevar adjunto y de manera fija una etiqueta evidente, de al menos 2 pulgadas $(5.08 \mathrm{~cm})$ por 3 pulgadas $(7.62 \mathrm{~cm})$ de grande, y enunciados estampados o impresos de manera visible en inglés y en letra imprenta de tamaño no menor a $1 / 3$ de pulgada $(8.38 \mathrm{~mm})$ de alto, indicando que el relleno que contiene está compuesto total o parcialmente de "relleno reutilizado," "relleno de segunda mano," "relleno ya usado," o "relleno usado."

\section{Para información más detallada, vea lo concerniente a la FTC en cuanto a:}

Hile su Camino hacia los Requerimientos de Etiquetado según las Leyes sobre Textiles y Lana.

\section{Afirmaciones Sobre Bambú}

Si un producto textil contiene rayón, la FTC exige al comercializador que etiquete el producto con contenido de rayón sin importar la fuente del material utilizado para crear el rayón. Las Reglas Textiles no prohibirán el uso no engañoso del término bambú para describir la fuente de las fibras de rayón en el producto, como "Rayón hecho de bambú." Si el producto contiene fibras de bambú que no se hayan convertido en rayón o en alguna otra fibra fabricada, la FTC exige al comercializador que etiquete el producto como si contuviera bambú. Para promocionar o etiquetar un producto con contenido de bambú en vez de rayón se exige evidencia competente y confiable, como pruebas científicas y análisis, para comprobar que en realidad está hecho de fibra de bambú que no se ha transformado en alguna otra fibra como el rayón. La misma norma aplica para otras afirmaciones, como aquellas que dicen que las fibras de rayón hechas de bambú retienen las propiedades naturales antimicrobianas de la planta de bambú. 


\section{Para información más detallada, vea lo relevante a los requerimientos de la FTC en cuanto a: ¿¿ómo evitar 'Bambúlizar' a sus Clientes?}

\section{Ley de 1939 sobre el Etiquetado de Productos de Lana}

Título 15, Código de los Estados Unidos, Capítulo 2, Sub Capítulo III, Sección 68

16 CFR 300 Reglas y Reglamentos según la Ley de 1939 sobre el Etiquetado de Productos de Lana La importación, fabricación, venta, puesta en venta, transporte para la venta, distribución, o publicidad de cualquier producto de lana que se promocione de manera falsa o engañosa o que falsifique una marca es ilegal y se considera un método injusto de competencia, así como una acción o práctica injusta y engañosa en el comercio bajo la Ley de la FTC. La Ley sobre el Etiquetado de Productos de Lana exige a los comercializadores que adhieran una etiqueta a cada uno de los productos de lana en el que se diga que:

- Los porcentajes se dan por el peso de la lana, lana reciclada y otras fibras que componen en un $5 \%$ o más el producto, y el total de todas las demás fibras;

- El porcentaje máximo del peso total del producto de lana de cualquier otro material no fibroso;

- El nombre bajo el cual el fabricante u otra empresa responsable negocia o quien lo haga en lugar de aquellos, el número de identificación registrado ("RN") de dicha empresa; y

- El nombre del país en donde se procesó o fabricó el producto de lana.

Una modificación realizada en 2014 a las Reglas para Lana permite que ciertas etiquetas colgables lleven el nombre genérico de las fibras, la marca, o las características de la fibra que no divulguen el contenido total de fibras del producto; sin embargo, si el producto de lana contiene alguna otra fibra, la etiqueta colgable debe decir clara y visiblemente que no informa sobre el contenido total de fibras del producto (por ejemplo, "Esta etiqueta no divulga el contenido completo de las fibras del producto" o "Ver etiqueta interna para el contenido total de fibras del producto").

La Ley sobre la Lana también contiene disposiciones sobre publicidad y gestión de archivos.

Los productos que contengan fibra de otros animales deben cumplir con cualquiera de las leyes de Etiquetado para Productos de Piel o Identificación de Productos Textiles.

\section{Para información más detallada, vea lo relevante a los requerimientos de la FTC en cuanto a: \\ Hile su Camino hacia los Requerimientos de Etiquetado según las Leyes sobre Textiles y Lana. \\ Sello de Cachemir: Cómo Cumplir con la Ley sobre el Etiquetado de Productos de Lana}




\section{Ley sobre el Etiquetado de Productos de Piel (FPLA)}

Título 15, Código de los Estados Unidos, Capítulo 2, Sub Capítulo IV, Sección 69

16 CFR 301, Reglas y Reglamentos Según la Ley sobre el Etiquetado de Productos de Piel (FPLA)

Todas las prendas de vestir fabricadas, importadas, o vendidas que contengan piel deben cumplir con los requerimientos de etiquetado según la Ley sobre el Etiquetado de Productos de Piel (FPLA). Los productos de piel - fabricados total o parcialmente con piel deben tener una etiqueta que informe:

- Si la piel es natural o insertada, blanqueada, o teñida;

- El nombre del animal;

- Si más del $10 \%$ del área de superficie del producto es piel;

- El país de origen de los productos importados de piel, incluyendo el país de origen de las pieles importadas que contienen los productos de piel en los Estados Unidos;

- Cualquier otra información que se requiera o permita;

- El nombre o número de identificación registrado ("RN") del fabricante o comercializador;

- Si la piel está usada o dañada.

La información solicitada anteriormente también debe aparecer en las facturas y en la publicidad de los productos de piel.

Los productos nacionales de piel pueden etiquetarse de forma que muestren el origen, aunque la ley no lo requiera. Las pieles nacionales también se pueden etiquetar para mostrar el estado particular o la parte del país en la que se originaron.

\section{Ley de 2010 sobre Información Real en el Etiquetado de Pieles}

Ley Pública 111-313

En diciembre de 2010, el Congreso aprobó la Ley sobre Información Real en el Etiquetado de Pieles. A partir del 18 de marzo de 2011, la excepción de la FTC a la Ley sobre el Etiquetado de Productos de Piel para los productos de piel con un valor por componente de USD\$150 o menos ya no estaba vigente.

\section{Para información más detallada, vea lo relevante a los requerimientos de la FTC en} cuanto a:

¿Cómo cumplir con la Ley sobre el Etiquetado de Productos de Piel, Prendas de vestir y Textiles? 


\section{Productos de Piel de Perro y Gato}

\section{Ley Arancelaria de 1930, Prohibición de Importación de Productos de Piel de Perro y Gato}

Título 19, Código de los Estados Unidos, Capítulo 4, Sección 1308

La regla 19 USC 1308 prohíbe la importación, exportación, distribución, transporte, fabricación o venta en los Estados Unidos de productos que contengan piel de perro o gato. A partir de noviembre 9 de 2000, La ley de 2000 sobre la Protección de Perros y Gatos exige el decomiso y confiscación de cualquier ítem que contenga piel de gato o perro. Esta Ley modificó a la Ley sobre el Etiquetado de Productos de Piel para excluir productos con piel de perro y gato de aquellos ítems autorizados por la FTC para eximirlos del etiquetado y otros requerimientos de la Ley sobre Pieles y sus reglamentos.

\section{Productos de Cuero}

16 CFR 24, Lineamientos para Productos de Selección e Imitación de Cuero

Estos lineamientos aplican para la fabricación, venta, distribución, comercialización, o publicidad de toda clase o tipo de cuero o imitación de cuero, incluyendo calzado.

\section{Afirmaciones Ambientales}

16 CFR 260, Lineamientos para el Uso de Afirmaciones Ambientales para la Comercialización de Productos

Estos lineamentos aplican para las afirmaciones ambientales incluidas en el etiquetado, la publicidad, los materiales promocionales y todas las otras formas de mercadeo, sea que se haga de manera directa o implícita, a través de palabras, símbolos, emblemas, logos, representaciones, marcas de productos, o a través de cualquier otra forma, incluyendo mercadeo en medios electrónicos o digitales, como la Internet o correo electrónico. Los lineamientos aplican para cualquier tipo de afirmación sobre los atributos ambientales de un producto, empaque, o servicio relacionado con la venta, puesta en venta, o comercialización de dicho producto, empaque, o servicio personal, familiar o para uso doméstico, comercial, institucional o industrial.

En 2012, una actualización hecha por la FTC modificó los lineamientos existentes de las secciones relacionadas con las afirmaciones sobre el beneficio ambiental, abono ecológico, materiales degradables, capa de ozono, materiales reciclables, y contenido ambiental en general. También incluyó nuevas secciones sobre la emisión de carbono, certificaciones y sellos de aprobación, afirmaciones sobre materiales libres de otros componentes, afirmaciones sobre materiales libres de componentes tóxicos, afirmaciones de productos hechos con energía renovable, y afirmaciones de productos hechos con materiales renovables.

\section{Para información más detallada, vea lo relevante a los requerimientos de la FTC en cuanto a:}

Afirmaciones Ambientales: Resumen de Lineamientos Ambientales 


\section{Etiquetas de Cuidado}

16 CFR 423, Etiqueta de Cuidado para Prendas Textiles de Vestir y Ciertas Mercancías en Piezas Según se Modifiquen

La Regla de Etiquetado de Cuidado de la Comisión Federal de Comercio (FTC) exige a los fabricantes y a los importadores que adjunten instrucciones de cuidado a las prendas de vestir. La Regla exige que los fabricantes o importadores cumplan con lo siguiente:

- Brindar instrucciones sobre el procedimiento de cuidado normal para la prenda, o dar precauciones en caso de que la prenda no se pueda limpiar sin causarle daños.

- Tener una justificación razonable para las instrucciones de la etiqueta de cuidado, incluyendo que el seguirlas, no causará ningún daño importante al producto.

- Prevenir a los consumidores sobre ciertos procedimientos que puedan asumir para que sean consistentes con las instrucciones de la etiqueta, pero que podrían dañar el producto. Por ejemplo, si un pantalón tiene una etiqueta para lavado, los consumidores pueden asumir que pueden también plancharlo. Si el pantalón se daña al plancharlo, la etiqueta debe indicar: "No planchar."

- Asegurarse de que las Etiquetas de Cuidado permanezcan adheridas y legibles durante la vida útil del producto.

Las Etiquetas de Cuidado deben adherirse a los productos antes de su venta en los Estados Unidos; sin embargo, estas etiquetas no tienen que adherirse a los productos cuando ingresan a los Estados Unidos. El importador debe asegurarse de que las etiquetas se encuentran adheridas antes de que el producto se venda.

Las etiquetas deben adherirse de manera permanente, segura, y deben ser legibles durante la vida útil del producto y deben verse o encontrarse fácilmente por parte de los consumidores en el punto de venta. Para los artículos que vengan empacados, la etiqueta de cuidado debe aparecer también en la parte exterior del empaque o en una etiqueta colgable en caso de que la etiqueta adherida al producto no se pueda ver claramente a través del empaque.

\section{Para información más detallada, vea lo relevante a los requerimientos de la FTC en cuanto a: \\ Textos de las Prendas de Vestir: Cumplimiento con la Regla de la Etiqueta de Cuidado y Recursos Legales para las Prendas de Vestir y los Textiles}

\section{Reglamentos Pendientes de Notificación}

En 2012, la FTC publicó la Regla de la Etiqueta de Cuidado en el Registro Federal en una Notificación sobre Legislación Propuesta (NPRM). La notificación especifica las modificaciones en consideración y solicita comentarios. Ver: 
Notificación sobre Legislación Propuesta: Regla de Regulación a la Comercialización sobre la Etiqueta de Cuidado de Prendas Textiles de Vestir y Ciertas Mercancías en Piezas (septiembre $\underline{20 \text { de } 2012 \text { ) }}$

\section{Departamento de Agricultura de los Estados Unidos (USDA)}

\section{Fibras Ecológicas: Ley de 1990 sobre la Producción de Alimentos Ecológicos (OFPA)}

Título 7, Código de los Estados Unidos, Capítulo 94, Certificación Orgánica, Secciones 6501-6523 EI USDA regula el término ecológico ya que aplica para los productos agrícolas a través de la Reglamentación del Programa Ecológico Nacional (NOP, siglas en inglés), 7 CFR Parte 205. Las fibras naturales sin procesamiento, como el algodón, la lana, y el lino son productos agrícolas y se encuentran cubiertos por las normas de los cultivos del NOP y la producción de ganadería. Todo producto textil producido según los reglamentos del NOP, incluyendo estar certificado por un tercero aprobado, puede etiquetarse como un producto ecológico certificado por el NOP y llevar el sello ecológico del USDA. Los productos fabricados según la Norma Global para Textiles Ecológicos (GOTS) se pueden comercializar como ecológicos en los Estados Unidos, pero no podrán referirse al certificado del NOP o llevar el sello ecológico del USDA.

\section{Para información más detallada, vea lo relevante a los requerimientos del USDA en cuanto a:}

Memorando de Políticas - Etiquetado de Textiles que Contengan Ingredientes Ecológicos y Manual del Programa Ecológico Nacional

\section{GENERALIDADES DE LOS MARCOS REGLAMENTARIOS DEL ESTADO ESTADOUNIDENSE}

Un número creciente de áreas se encuentran amparadas tanto por las leyes estatales como las federales, incluyendo la protección al consumidor, el empleo y las reglamentaciones sobre alimentos y medicinas. (Las leyes estatales permiten que las leyes federales, aún más estrictas, reglamenten el mismo asunto.) Cuando el Gobernador de un estado firma una ley, esta se convierte en una ley estatal. Una vez se ha promulgado la ley por parte de un estado, es responsabilidad de la agencia correspondiente del estado crear los reglamentos necesarios para implementar la ley. 


\section{AUTORIDADES REGULADORAS ESTATALES Y REGLAMENTOS TÉCNICOS (OBLIGARTORIO)}

En los Estados Unidos, algunas leyes y reglamentos estatales promulgadas son más estrictas que las leyes federales. Dichas leyes incluyen reglamentos para los productos, el proceso de etiquetado, empaque, restricciones químicas, etc. Los estados de California y New York tienen regulaciones bastante exhaustivas para muchos de los productos de consumo.

\begin{tabular}{|l|l|}
\hline Agencia/Organización & Alcance \\
\hline $\begin{array}{l}\text { Autoridades Estatales Responsables por los Pesos y } \\
\text { Medidas }\end{array}$ & Etiquetado \\
\hline $\begin{array}{l}\text { Centro de Información Sobre Tóxicos en Empaques } \\
\text { (TPCH, siglas en inglés) }\end{array}$ & Empaquetado \\
\hline $\begin{array}{l}\text { Asociación Internacional de Funcionarios Jurídicos para } \\
\text { la Industria de las Prendas de Cama y Muebles (IABFLO, } \\
\text { siglas en inglés) }\end{array}$ & Etiquetado \\
\hline $\begin{array}{l}\text { Oficina de Evaluación de Peligros a la Salud Ambiental } \\
\text { de California (OEHHA) }\end{array}$ & Químicos Tóxicos \\
\hline $\begin{array}{l}\text { Oficina de Reparaciones Electrónicas y de } \\
\text { Electrodomésticos, Mobiliario y Aislamiento Térmico del } \\
\text { Estado de California (BEARHFTI) }\end{array}$ & $\begin{array}{l}\text { Plumaje, inflamabilidad de mobiliario } \\
\text { tapizado y prendas de cama }\end{array}$ \\
\hline $\begin{array}{l}\text { Departamento de Asuntos del Consumidor del Estado de } \\
\text { California }\end{array}$ & $\begin{array}{l}\text { Afirmaciones de productos hechos en } \\
\text { Estados Unidos }\end{array}$ \\
\hline $\begin{array}{l}\text { Departamento de Protección al Consumidor del Estado } \\
\text { de Connecticut }\end{array}$ & Asbestos en productos para niños \\
\hline Departamento de Salud Pública del Estado de Illinois & Etiquetado de plomo \\
\hline Departamento de Comercio del Estado de Minnesota & $\begin{array}{l}\text { Formaldehído en productos para } \\
\text { niños }\end{array}$ \\
\hline Departamento de Ecología del Estado de Washington & $\begin{array}{l}\text { Plomo, cadmio y ftalatos en } \\
\text { productos para niños }\end{array}$ \\
\hline $\begin{array}{l}\text { Varios estados } \\
\text { Retardantes de llamas, etiquetado } \\
\text { para productos con pieles, químicos } \\
\text { de preocupación. }\end{array}$ \\
\hline
\end{tabular}

\section{Empaquetado y Etiquetado}

\section{UPLR}

Los Reglamentos Uniformes de Empaquetado y Etiquetado (UPLR) en las Leyes y Reglamentos Uniformes para las Áreas de Metrología Legal y Calidad de Combustible de Motores, Manual del NIST 130, se han adoptado en la ley 45 de los 50 estados estadounidenses. El propósito de dichos reglamentos es ofrecer información precisa y adecuada sobre la identidad y cantidad del 
contenido de los empaques de forma tal que los compradores puedan realizar comparaciones de precio y cantidad.

Los UPLR exigen que el empaque de consumo lleve una etiqueta en la que se especifique la identidad del bien básico; el nombre y el domicilio comercial del fabricante, empaquetador, o distribuidor; y la cantidad neta del contenido en términos de peso o masa, o el conteo numérico de forma uniforme con respecto al panel principal de visualización.

\section{Tóxicos en la Legislación de Empaquetado}

Esta legislación modelo originalmente la redactó el Consejo de Reducción de Fuentes de Materiales de la Coalición de Gobernadores del Noreste (CONEG) en 1989. Se desarrolló en un esfuerzo por reducir la cantidad de metales pesados en el empaquetado y en los componentes de los empaques que se vendían o distribuían a lo largo de los Estados Unidos. La ley se diseñó para eliminar progresivamente el uso y la presencia de mercurio, plomo, cadmio, y cromo hexavalente en los empaques de productos. La legislación se ha adoptado con éxito en 19 estados.

Para información más detallada, ver la Documentación Técnica sobre Centro de Información Sobre Tóxicos en Empaques: Ficha Descriptiva de Tóxicos en Empaques de Productos.

\section{Etiqueta de Ley Uniforme}

Las prendas de cama con relleno, prendas de vestir, textiles, bolsas para dormir y juguetes vendidos en los Estados Unidos requieren una etiqueta especial. Treinta y un estados, incluyendo a los estados de California, Massachusetts, New York, Ohio y Pennsylvania, han promulgado leyes que exigen el etiquetado de prendas de cama, prendas de vestir tapizadas y textiles. Para simplificar el cumplimiento con las leyes de etiquetado de los diferentes estados para las prendas de cama, las prendas de vestir tapizadas y textiles, la Asociación Internacional de Funcionarios Jurídicos para la Industria de las Prendas de Cama y Muebles (IABFLO), compuesta por funcionarios estatales responsables del cumplimiento de las leyes concernientes a las prendas de cama, prendas de vestir y textiles en sus correspondientes estados, establecieron un Sistema de Etiquetado de Ley Uniforme para brindar ayuda a los fabricantes.

La Etiqueta de Ley dispone que se debe describir el material de relleno del artículo en términos de porcentaje de dicho relleno según su peso. Por ejemplo, $80 \%$ espuma de poliuretano, $20 \%$ de fibras de poliéster. También especifica que "BAJO PENA DE LEY ESTA ETIQUETA SOLO LA PUEDE REMOVER EL CONSUMIDOR" cuando se use en prendas para cama, prendas de vestir y textiles. Los productos a los que afecta la Etiqueta de Ley en cada uno de los estados varía, así como sus correspondientes requerimientos de etiquetado. La Etiqueta de Ley Uniforme se puede utilizar para satisfacer los diferentes requerimientos de cada estado. 
La Etiqueta de Ley también exige en la mayoría de estados que se muestre un Número Uniforme de Registro que identifique las instalaciones de fabricación en donde se originó el producto. Aplica para cualquier empresa en el mundo que venda sus productos en los Estados Unidos. Una etiqueta de ley NO podrá combinarse con ninguna otra etiqueta. Sin embargo, se acepta poner una línea en negrilla entre una etiqueta de ley y la etiqueta de inflamabilidad de California (impresa de lado a lado para verse como dos etiquetas separadas).

Para información más detallada, ver

Prendas de Cama \& Mobiliarios y Ejemplos de Etiquetas de Ley para Prendas de Cama de la IABFLO.

Manual Técnico Estadounidense de Etiquetas de Ley: American Law Label, Inc. (incluye productos a los que aplica y exenciones)

\section{Estado de California}

\section{Plomo y Otras Sustancias Tóxicas}

California regula el contenido de plomo y otras muchas más sustancias y químicos, tanto en productos para adultos como para niños, mediante su Ley de Agua Potable Segura y Control de Sustancias Tóxicas de 1986, conocida popularmente como La Propuesta 65 o Prop 65 (Código de Salud y Seguridad de California. Sección 25249.6, et seq.) Han existido varios acuerdos relativos a los químicos como el plomo, DEHP (ftalatos), y retardantes de llama en prendas de vestir y textiles. Dichos acuerdos ofrecen lineamientos para límites sugeridos. El Listado de Sustancias Peligrosas de la Propuesta 65 se revisa y actualiza a medida que se identifican nuevos químicos.

El siguiente lenguaje de precaución se exige en productos vendidos en California en caso de contener químicos del listado de la Propuesta 65 y si la cantidad de exposición causada por el producto no se encuentra dentro de los límites definidos de seguridad:

ADVERTENCIA: Este producto contiene químicos conocidos por el Estado de California debidd a que causan cáncer y defectos de nacimiento u otros daños reproductivos.

Para información oficial más detallada sobre la Propuesta 65 del Estado de California, ver:

Oficina de Evaluación de Peligros a la Salud Ambiental de California (OEHHA), Propuesta 65 en Lenguaje Sencillo, y ver también Novedades de la Propuesta 65

\section{Reglamentos para Productos de Consumo más Seguros}

Los Reglamentos para Productos de Consumo más Seguros aplican a todos los productos de consumo puestos en el flujo comercial del Estado de California. Exige a los fabricantes o a otras 
entidades responsables que busquen alternativas más seguras para los ingredientes químicos dañinos en productos ampliamente utilizados. Estos reglamentos exigen que el Departamento de Sustancias Tóxicas adopte reglamentos que establezcan un proceso de identificación y priorización de químicos en productos de consumo y que establezcan un proceso de evaluación de químicos de preocupación en productos de consumo y sus alternativas potenciales.

\title{
Para información más detallada, ver: ¿Cuáles son los Reglamentos para Obtener Productos de Consumo más Seguros?
}

\author{
Reglamentos Sobre Plumaje \\ El Artículo 5 de la Oficina de Reglas y Reglamentos para Mobiliarios y Aislamiento Térmico del \\ Departamento de Asuntos del Consumidor establece los requerimientos de etiquetado según el \\ porcentaje mínimo de plumones y plumas.
}

\section{Inflamabilidad de Mobiliario Tapizado y Prendas de Cama}

La Oficina de Reparaciones Electrónicas y de Electrodomésticos, Mobiliario y Aislamiento Térmico del Estado de California (BEARHFTI) regula (4 CCR § 1370-13774.3) la Inflamabilidad del mobiliario tapizado y las prendas de cama independientemente de su punto de origen. Dichos reglamentos incluyen pruebas específicas y requerimientos de etiquetado que se especifican en los reglamentos y en el Boletín Técnico 117-2013 - Requerimientos, Procedimientos para Pruebas y Aparatos para Realizar Pruebas de Resistencia al Fuego de Materiales Usados en Mobiliario Tapizado.

La norma de inflamabilidad TB117-2013 aplica al mobiliario tapizado vendido en California. Los productos de prendas de cama como colchones, edredones, protectores para colchón, almohadas y almohadas decorativas no están sujetos a la norma TB117-2013. Sin embargo, deben portar una etiqueta de ley.

El Capítulo 862 del Estado de California promulgada el 30 de septiembre de 2014, exige a los fabricantes de productos cubiertos, según se definen, que indiquen en la etiqueta si el producto contiene o no químicos retardantes de llamas al incluir una frase específica en dicha etiqueta. La frase debe seguir los requerimientos de etiquetado de la norma TB 117 en la misma etiqueta. La ley también exige a los fabricantes que archiven la documentación que compruebe la información puesta en la etiqueta.

Actualmente, varios ítems se encuentran exentos bajo el Código de Regulación de California en la Sección 1374.2, incluyendo caminadores, cargadores de bebés y almohadas de lactancia; cojines y almohadillas diseñadas exclusivamente para utilizar al aire libre; y todo artículo de superficie lisa que contenga material de relleno en cantidades que no excedan media pulgada, 
siempre y cuando dicho artículo no tenga una superficie horizontal que se una con una superficie vertical.

Para información más detallada, ver lo concerniente a la BEARHFTI en cuanto a: Boletín Técnico 117-2013, Sección de Preguntas Frecuentes, Reglas y Reglamentos y Orden de Adopción - Criterios de Exenciones

\section{Hecho en los Estados Unidos de América}

Una ley reciente volvió más suave la estricta Ley californiana de "Hecho en los Estados Unidos de América". Bajo la ley revisada las etiquetas de "Hecho en los Estados Unidos de América", "Hecho en América", "U.S.A" o etiquetas similares se permiten incluso si un producto tiene algún componente extranjero. Se permite el etiquetado si dicho componente extranjero o parte no excede el $5 \%$ del valor total generalizado del producto o si algún componente extranjero o parte no constituye más del $10 \%$ del valor final generalizado del producto y el fabricante puede demostrar que dichos componentes no se pueden obtener o producir dentro del país.

\section{Estado de Connecticut}

\section{Productos Seguros para Niños}

Más allá de los reglamentos federales de seguridad para niños, esta Ley prohíbe la introducción o entrega para introducir al comercio cualquier juguete u otro artículo que contenga asbestos para su venta en el Estado de Connecticut y cuyo público objetivo sea niños menores de 16 años de edad.

\section{Estado de Illinois}

\section{Plomo}

Ley Pública 097-0612, Ley de Prevención de Envenenamiento por Plomo

La Ley vuelve ilegal vender o repartir cualquier tipo de sustancia que contenga plomo y que pueda utilizarse por el público en general, a menos de que lleve una advertencia como la que se presenta a continuación, o según lo prescriba alguna otra regulación federal. La advertencia deberá estar ubicada en un lugar visible en el ítem o su empaque (16 CFR $\underline{1500.121})$. Si no hay ninguna regulación federal sobre el asunto, la advertencia será la siguiente cuando la sustancia que contenga plomo lo tenga en su pintura o en una forma distinta a la pintura con plomo: 
"ADVERTENCIA: CONTIENE PLOMO. PUEDE SER DAÑINO SI SE CONSUME O MASCA. PUEDE GENERAR POLVO CON CONTENIDO DE PLOMO. MATÉNGANSE FUERA DEL ALCANCE DE LOS NIÑOS."

Si no hay ninguna reglamentación al respecto, la advertencia deberá ser la siguiente cuando la sustancia que contenga plomo sea pintura a base de plomo o revestimiento de superficies a base de plomo:

"ADVERTENCIA - CONTIENE PLOMO. PUEDE SER DAÑINO SI SE CONSUME O MASCA. Ver Otras Precauciones en el panel (lateral o trasero). No aplicar en juguetes o en otros artículos para niños, muebles o en superficies internas o externas expuestas de cualquier unidad residencial o instalación física en la que puedan vivir niños o que pueda ser usada por niños. MANTÉNGASE FUERA DEL ALCANCE DE LOS NIÑOS."

La frase de advertencia no aplica para ningún producto para el cual la ley federal rija la advertencia de forma que remplace a la autoridad estatal.

\section{Estado de Minnesota}

\section{Formaldehído en Productos para Niños}

El Estado de Minnesota prohíbe la venta de ciertos productos diseñados para niños de 8 años de edad y menos que contengan formaldehídos de manera deliberada o cuyos ingredientes se degraden en formaldehídos. Se define como productos para niños, para el propósito de esta ley, todo producto diseñado principalmente o proyectado por un fabricante para aplicarse físicamente a o introducido en el cuerpo de un/a niño/a, incluyendo todo artículo que se use como componente de dicho producto, excluyendo alimentos, bebidas, suplementos dietarios, productos farmacéuticos o biológicos, juguetes para niños (amparados por las reglas de la CPSC), o dispositivos médicos (amparados por las reglas del FDA).

\section{Estado de Washington}

\section{Plomo, Cadmio, y Ftalatos en Productos para Niños}

La Ley de Productos Seguros para Niños del Estado de Washington restringe la venta de productos para niños que contengan más del $0.009 \%$ de su peso total en plomo; más de $0.004 \%$ de su peso total en cadmio, o $0.10 \%$ de su peso total en ftalatos, de manera individual o combinados. 
Los límites y el alcance de esta ley son más estrictos que los requerimientos federales actuales. Los productos amparados bajo esta Ley incluyen cosméticos para niños; joyería; juguetes; sillas de automóvil; y artículos de cuidado infantil, incluyendo prendas de vestir y calzado.

Ver lo relativo al Departamento de Ecología del Estado de Washington en: La Página Web de la Ley sobre Productos Seguros para Niños

\section{Varios Estados}

\section{Reglamentos sobre Retardantes de Llama}

Varios estados estadounidenses tienen una legislación que prohíbe el uso de retardantes de llama, como el Pentabromodifelino, Octabromodifelino, Decabromodifelino, el TCEP, y el tris clorinado, en productos, incluyendo mobiliario tapizado y productos para niños. El grupo de estados con esta legislación incluye: Hawaii, Illinois, Maine, Maryland, Michigan, Minnesota, New York, Oregón, Rhode Island, Vermont y Washington. Se ha propuesto la legislación en los siguientes estados: Alaska, California, Connecticut, Delaware, Massachusetts, New York, North Carolina, Ohio, Rhode Island y Washington.

\section{Etiquetado de Pieles}

Los Estados de Delaware, Massachusetts, New Jersey, New York, y Wisconsin han promulgado una legislación para el etiquetado de productos de piel. El Estado de Delaware exige que todas las prendas de vestir que contengan pieles reales (total o parcialmente) Ileven adherido y de manera visible una etiqueta, adhesivo o aviso en las prendas de vestir en el que se declare que dicho producto se fabricó con piel. Bajo la legislación del Estado de Massachusetts, todas las pieles naturales, tinturadas o de imitación, así como todos los artículos fabricados total o parciamente con pieles y que se vendan al por menor dentro de la mancomunidad, deberán estar marcados o etiquetados mediante una declaración exacta sobre los materiales que contienen, junto con el nombre y la dirección del vendedor. La ley del Estado de New Jersey exige que todo abrigo, chaqueta, prenda de vestir o cualquier otro tipo de prenda nueva fabricada total o parcialmente con pieles, sin importar el precio o el valor de la piel, no se podrá vender a menos que tenga adherida y de manera visible una etiqueta o aviso que incluya el nombre del o de los animales utilizados para la fabricación del producto de piel, y el nombre del país de origen de la piel importada. La ley del Estado de New York considera ilegal vender cualquier producto de piel real o de imitación que no se encuentre adecuadamente etiquetado. La ley del Estado de Wisconsin señala que ninguna persona deberá vender, poner en venta o exhibir para la venta ningún tipo de abrigo, chaqueta u otro tipo de prenda de vestir con un valor mayor a los USD\$50 que haya sido fabricada total o parcialmente con piel sin una etiqueta que especifique en inglés la especie de piel o cuero utilizado. 


\section{Pieles de Perro y Gato}

Adicionalmente a la prohibición federal, el Estado de New York tiene una reglamentación similar. Prohíbe la venta de pieles, cuero, pelo, o carne de un perro o un gato y exige a los fabricantes o proveedores que presenten una certificación a cada uno de los vendedores al detal de que ninguno de sus productos contiene piel, cuero, pelo o carne de perros o gatos domesticados.

\section{Químicos de Preocupación}

Varios estados, incluyendo los estados de Oregón, Washington, Vermont y Maine, exigen a los fabricantes que venden productos para niños que contengan algún químico incluido en la lista estatal de Químicos de Preocupación que proporcionen una notificación al estado antes de comenzar las actividades de venta en dicho estado. En algunos casos, el fabricante deberá retirar o sustituir el químico de sus productos.

\section{Acolchados para Cunas}

El Estado de Maryland y la ciudad de Chicago han prohibido la venta de paño para acolchados para cunas. La prohibición en el Estado de Maryland afecta a los acolchados para cunas que estén fabricados con materiales que no contengan enmallado, que se pongan directamente sobre el colchón a lo largo de cada lado interno de la cuna, y que se hayan diseñado para usarse hasta la edad en la que un bebé se incorpore para pararse. El Estado de Illinois se encuentra estudiando una legislación similar.

\section{GeNERALIDADES DEL MARCO DE NORMAS VoluntaRIAS DE LOS ESTADOS UNIDOS}

El sistema de desarrollo de normas de Los Estados Unidos está impulsado por el sector privado. La mayoría de las normas estadounidenses son voluntarias y se desarrollan a través de métodos de consenso que reflejan las necesidades de los productores y fabricantes, los usuarios y los consumidores, y el gobierno. El Instituto Nacional Estadounidense de Estándares (ANSI) (organización no gubernamental sin ánimo de lucro) coordina la mayoría de las actividades de desarrollo de las normas voluntarias del sector privado en los Estados Unidos. Existen cientos de Organizaciones Desarrolladoras de Normas Voluntarias en los Estados Unidos que son responsables de la normalización en varios y diferentes sectores industriales y empresariales. El Instituto Nacional de Normas y Tecnología (NIST), es parte del Departamento de Comercio de los Estados Unidos, y es el laboratorio nacional de metrología para los Estados Unidos. El NIST proporciona la infraestructura técnica de medida para apoyar el comercio global y el sistema comercial de medida. EI NIST, a través de su Oficina de Coordinación de Normas, asesora y coordina la participación federal en el establecimiento de normas. 
Asociación Americana de Químicos y Coloristas Textiles (AATCC)

P.O. Box 12215

Research Triangle Park, NC 27709-2215 USA

Teléfono: +19195498141

Directorio de Funcionarios

La Asociación Americana de Químicos y Coloristas Textiles (AATCC) desarrolla métodos de prueba y procedimientos de evaluación para textiles y prendas de vestir. Dichos métodos se publican anualmente en el Manual Técnico de la AATCC.

Ejemplos de normas de la AATCC:

\begin{tabular}{|l|l|}
\hline $\begin{array}{l}\text { Análisis de la Actividad Antimicrobiana en Materiales } \\
\text { Textiles: Método de Agar en Placa }\end{array}$ & Método de prueba 90 \\
\hline $\begin{array}{l}\text { Fijación de color en desteñimiento de telas. Método de } \\
\text { Medición de Desteñimiento. }\end{array}$ & Método de prueba 8 \\
\hline $\begin{array}{l}\text { Fijación de color en desteñimiento de telas: Método de } \\
\text { rotación vertical para la medición de Desteñimiento. }\end{array}$ & Método de prueba 116 \\
\hline $\begin{array}{l}\text { Fijación de color en el desteñimiento de telas: } \\
\text { Revestimientos Para Suelos - Método de Medición de } \\
\text { Desteñimiento }\end{array}$ & Método de prueba 165 \\
\hline Fijación de color en Lavado en Seco & Método de prueba 132 \\
\hline Fijación de color en luz & Método de prueba 16 \\
\hline Fijación de color en Transpiración & Método de prueba 15 \\
\hline Fijación de color en Agua & Método de prueba 107 \\
\hline Análisis de Fibras: Cualitativo & Método de prueba 20 \\
\hline Análisis de Fibras: Cuantitativo & Método de prueba $20 \mathrm{~A}$ \\
\hline Terminados en Textiles: Identificación & Método de prueba 94 \\
\hline Resistencia al Desgaste de Telas: Método de Acelerotor & Método de prueba 93 \\
\hline Absorbencia de Textiles & Método de prueba 79 \\
\hline $\begin{array}{l}\text { Apariencia de Prendas de Vestir y Otros Productos Textiles } \\
\text { Finales Después de Varios Lavados en Casa }\end{array}$ & Método de prueba 143 \\
\hline $\begin{array}{l}\text { Alfombras: Limpieza de Alfombras, Método de Extracción } \\
\text { con Agua Caliente }\end{array}$ & Método de prueba 171 \\
\hline Alfombras: Propensión Electrostática de las alfombras & Método de prueba 134 \\
\hline $\begin{array}{l}\text { Resistencia a las Manchas: Pilas de Revestimientos para } \\
\text { Suelos }\end{array}$ & Método de prueba 175 \\
\hline Resistencia al Agua: Pruebe de Lluvia & Método de prueba 35 \\
\hline
\end{tabular}




\section{ASTM International}

100 Barr Harbor Drive

P.O. Box C700

West Conshohocken, PA 19428-2959 USA

Teléfono: + 1.610.832.9500

Directorio de Funcionarios

ASTM International (ASTM) desarrolla y revisa las normas de consenso y los métodos de prueba para las prendas de vestir y los textiles. Una gran cantidad de normas ASTM o métodos de prueba se han "Incluido por Referencia" en el CFR (como se citó anteriormente bajo la CPSC), y son obligatorias.

El Comité de ASTM es el responsable del Comité D13 para prendas de vestir y textiles.

Los siguientes subcomités de ASTM son relevantes para las prendas de vestir y textiles para hogar:

\begin{tabular}{|l|l|}
\hline$\underline{D 13.11}$ & Fibras de algodón \\
\hline$\underline{\mathrm{D} 13.13}$ & Lana y Fieltro \\
\hline$\underline{\mathrm{D} 13.16}$ & Sogas y Cordaje \\
\hline$\underline{\mathrm{D} 13.18}$ & Lino y Prendas de Cama \\
\hline$\underline{\mathrm{D} 13.19}$ & Fibra de Vidrio y sus Productos \\
\hline$\underline{\mathrm{D} 13.20}$ & Fibras industriales y Refuerzos Metálicos \\
\hline$\underline{\mathrm{D} 13.21}$ & Restricciones a Inflables \\
\hline$\underline{\mathrm{D} 13.40}$ & Pilas de Revestimiento para Suelos \\
\hline$\underline{\mathrm{D} 13.51}$ & Sostenibilidad de los Textiles \\
\hline$\underline{\mathrm{D} 13.52}$ & Acondicionamiento y Propiedades Químicas y Térmicas \\
\hline$\underline{\mathrm{D} 13.54}$ & Inflamabilidad \\
\hline$\underline{\mathrm{D} 13.55}$ & Subconjuntos \\
\hline$\underline{\mathrm{D} 13.58}$ & Medida de Cuerpos para Tallas de Prendas de Vestir \\
\hline$\underline{\mathrm{D} 13.59}$ & Hilos y Fibras \\
\hline$\underline{\mathrm{D} 13.60}$ & Métodos Generales de Pruebas para Telas \\
\hline$\underline{\mathrm{D} 13.61}$ & Métodos Específicos de Pruebas para Telas \\
\hline$\underline{\mathrm{D} 13.62}$ & Prendas de vestir \\
\hline$\underline{\mathrm{D} 13.63}$ & Etiquetado \\
\hline$\underline{\mathrm{D} 13.65}$ & Mobiliario para Hogar \\
\hline$\underline{\mathrm{D} 13.66}$ & Telas con Protección UV y Prendas de vestir \\
\hline & Automatización de Costura de Prendas \\
\hline
\end{tabular}


Algunos ejemplos sobre las normas para prendas de vestir y textiles para el hogar de ASTM incluyen:

\begin{tabular}{|l|l|}
\hline D1230 & $\begin{array}{l}\text { Método Estándar de prueba para Inflamabilidad de Prendas de } \\
\text { Vestir y Textiles }\end{array}$ \\
\hline D3691/D3691M & $\begin{array}{l}\text { Especificación Estándar de Desempeño para Tejidos, Encajes, y } \\
\text { Cortinas Tejidas para el Hogar y Telas de Paño }\end{array}$ \\
\hline D5489 & $\begin{array}{l}\text { Guía Estándar para Símbolos de Cuidado e Instrucciones de } \\
\text { Cuidado en Productos Textiles }\end{array}$ \\
\hline D276 & Método Estándar de Prueba para Identificar Fibras en Textiles \\
\hline D629 & Método Estándar Pruebas de Análisis Cuantitativo de Textiles \\
\hline D4964 & $\begin{array}{l}\text { Método Estándar de Pruebas para Tensión y Elongación de } \\
\text { Telas Elásticas (Tasa Constante de Extensión en Máquina de } \\
\text { Prueba de Resistencia Textil) }\end{array}$ \\
\hline D6614 & $\begin{array}{l}\text { Método Estándar de Pruebas de Propiedades Elásticas de Telas } \\
\text { Textiles - Método de Tasa Constante de Extensión CRE }\end{array}$ \\
\hline D6797 & $\begin{array}{l}\text { Método Estándar de Pruebas para la Resistencia al Estallido de } \\
\text { Telas mediante la Prueba de Tasa Constante de Extensión (CRE) } \\
\text { de Estallido de Pelotas }\end{array}$ \\
\hline D1230 & $\begin{array}{l}\text { Método Estándar de Pruebas para la Inflamabilidad de Prendas } \\
\text { de Vestir y Textiles }\end{array}$ \\
\hline D4151 & Método Estándar de Pruebas para la Inflamabilidad de Cobijas \\
\hline D6413/D6413M & $\begin{array}{l}\text { Método Estándar de Pruebas para la Resistencia a las Llamas de } \\
\text { Textiles (Prueba Vertical) }\end{array}$ \\
\hline D6545 & $\begin{array}{l}\text { Método Estándar de Pruebas para la Inflamabilidad de Textiles } \\
\text { Utilizados en Prendas de Dormir para Niños }\end{array}$ \\
\hline D3690 & $\begin{array}{l}\text { Especificación Estándar de Desempeño para Telas de Tapiz de } \\
\text { Uso Interior Recubiertas con Vinilo y Uretano }\end{array}$ \\
\hline
\end{tabular}

\section{Organismos de Pruebas y Certificaciones}

\section{Pruebas}

Para las prendas de vestir y textiles, refiérase al listado de Laboratorios Reconocidos por la CPSC. Los laboratorios también se pueden buscar por producto (por ejemplo, prendas de vestir) o por alcance (por ejemplo, 16 CFR Parte 1611, Inflamabilidad de Película de Vinilo).

Varios laboratorios prueban prendas de vestir y textiles para normas reconocidas en la industria; algunos pueden estar acreditados. Una lista de laboratorios acreditados se puede ver en el Listado de Laboratorios Acreditados por Prueba de la A2LA. Listados de otros laboratorios de pruebas se pueden encontrar en el Directorio de Laboratorios de Pruebas de la ASTM. Se 
puede realizar la búsqueda por palabra clave 'prendas de vestir y textiles' o mediante una norma específica de la ASTM.

\section{Certificación}

La Sección 102 de la CPSIA exige que todo fabricante o importador de cualquier producto de consumo sujeto a la regla de seguridad de productos de consumo impuesta por la CPSC genere un certificado en el que se diga que el producto cumple con la norma aplicable, la reglamentación o prohibición. Dicho certificado debe acompañar al producto y debe entregársele a minorista o distribuidor. La Sección 102 también exige a los fabricantes o a los importadores de productos para niños (de 12 años de edad o menos) que certifiquen que los productos cumplen con todas las normas relevantes de seguridad de los productos al generar un certificado de producto para niños apoyado por las pruebas realizadas por un laboratorio de pruebas externo aceptado por la CPSC.

\section{AgENCIAS GUBERNAMENTALES ESTADOUNIDENSES RELEVANTES}

\section{Oficina de Aduanas y Protección Fronteriza Estadounidense (CBP)}

1300 Pennsylvania Avenue, NW

Washington, D.C. 20229 USA

Teléfono: +1.703 .526 .4200$

Formulario en línea de Correo Electrónico

Para información más detallada, ver datos de la Comisión Internacional de Comercio de los Estados Unidos (USITC): Nomenclatura Arancelaria Armonizada de los Estados $\underline{\text { Unidos }}$

\section{Comisión de Seguridad de Productos del Consumidor de Estados Unidos (CPSC)}

4330 East West Highway

Bethesda, MD 20814 USA

Teléfono: +1.301.504.7923

Formulario en línea de Correo Electrónico

$\begin{array}{ll}\text { Oficina de la CPSC } & \text { Teléfono } \\ \begin{array}{l}\text { Oficina de Programas y Asuntos } \\ \text { Intergubernamentales }\end{array} & +1.301 .504 .7071 \\ \begin{array}{l}\text { Oficina De Cumplimiento y Operaciones } \\ \text { en Campo }\end{array} & +1.301 .504 .7915 \\ \begin{array}{l}\text { Subdirector } \\ \text { Oficina de Vigilancia de Importaciones }\end{array} & +1.301 .504 .7520 \\ & +1.301 .504 .7677\end{array}$




\section{Agencia de Protección Ambiental (EPA)}

Programa de Importaciones

2000 Traverwood Drive

Ann Arbor, MI 48105 USA

Teléfono: +1.734 .214 .4100$

Fax: +1.734.214.4676

Listado de Contactos

\section{Comisión Federal de Comercio}

600 Pennsylvania Avenue, NW

Washington, DC 20580 USA

Teléfono: +1.202.326.2222

Listado de Contactos

\section{Departamento de Agricultura de los Estados Unidos}

1400 Independence Avenue, SW

Washington, DC 20250 USA

Teléfono: +1.202.720.2791

\section{Datos de la Industria y el MeRCado Estadounidense DE PRENDAS DE VeStiR Y TeXtiles}

\section{PARA HOGAR}

\section{Asociaciones Comerciales de la Industria}

Asociación Americana del Vestuario y el Calzado (AAFA)

1601 North Kent Street, $12^{\text {th }}$ Floor

Arlington, VA 22209 USA

Teléfono: +1.703 .524 .1864 y +1.703 .522 .6741$

La AAFA es la asociación nacional en los Estados Unidos que representa a las compañías del vestuario, el calzado y otros productos de la confección y a sus proveedores. La AAFA publica en varios idiomas un Lista de Sustancias Restringidas (RSL) que brinda información relacionada con los reglamentos y leyes que restringen o prohíben ciertos químicos y sustancias en productos textiles finalizados para el hogar, prendas de vestir y calzado en todo el mundo. 
Asociación Internacional de Telas Industriales (IFAI)

1801 County Road B W

Roseville, MN 55113-4061 USA

Teléfono: +1 6512222508 o +1 8002254324

La Asociación Internacional de Telas Industriales es una asociación comercial sin ánimo de lucro compuesta por empresas miembro que representan el mercado internacional de telas especiales.

Asociación de la Industria de la Moda Estadounidense (USFIA)

1140 Connecticut Avenue, Suite 950

Washington, DC 20036 USA

Teléfono: +1 202-419-0444

La USFIA, anteriormente la Asociación de Importadores de Textiles \& Prendas de Vestir de los Estados Unidos, brinda espacios de educación, información y defensoría a ejecutivos activos en el suministro de textiles y prendas de vestir, importación, cumplimiento de normas y logística. La USFIA representa las necesidades de los minoristas estadounidenses, las marcas y los importadores, así como a los proveedores de servicios relacionados, con el objeto de eliminar los obstáculos al negocio y al comercio.

\section{Datos del Mercado de Prendas de Vestir y Textiles para el Hogar}

Asociación Americana del Vestuario y el Calzado (AAFA)

Tendencias: Análisis Estadístico Anual de las industrias de las Prendas de Vestir y el Calzado los Estados Unidos (2008)

Estadísticas Industriales

Oficina de Textiles y Prendas de Vestir (OTEXA)

Datos Comerciales: Importaciones y Exportaciones Estadounidenses de Textiles y Prendas de $\underline{\text { Vestir }}$ 
El Centro de Información sobre Estándares (SIC) del NIST realiza los esfuerzos necesarios para proporcionar información exacta y completa. Varios datos como nombres, números de teléfono, vínculos a las páginas web, etc., pueden cambiar antes de la actualización. Agradecemos sus sugerencias sobre cómo mejorar la presente guía y corregir los errores. El SIC brinda esta información "TAL CUAL APARECE." EI NIST y el SIC NO DAN NINGUNA GARANTÍA DE NINGÚN TIPO, incluyendo NINGUNA GARANTÍA DE COMERCIABILIDAD O ADECUACIÓN PARA NINGÚN PROPÓSITO ESPECÍFICO. EI NIST no garantiza ni asume responsabilidad alguna por la exactitud, precisión, integridad o confiabilidad de la información. Como condición para el uso de la guía de información, usted explícitamente libera al NIST/SIC de cualquier responsabilidad por cualquier daño o perjuicio de cualquier tipo causado que pueda resultar por los errores u omisiones en la presente Guía o cualquier otro dato. Algunos de los documentos que se referencian apuntan a información creada y revisada por otras organizaciones. El SIC no controla y no puede garantizar la relevancia, periodicidad o exactitud de dichos materiales.

Noviembre de 2017

Preparado por el Centro de Información sobre Estándares (SIC)

Coordinación de Normas (SCO)

Instituto Nacional de Normas y Tecnología (NIST)

standardsinfo@nist.gov

http://www.standards.gov 